\title{
Cannabinoids Elicit Antidepressant-Like Behavior and Activate Serotonergic Neurons through the Medial Prefrontal Cortex
}

\author{
Francis Rodriguez Bambico, ${ }^{1}$ Noam Katz, ${ }^{1,2}$ Guy Debonnel, ${ }^{1+}$ and Gabriella Gobbi ${ }^{1,2}$ \\ ${ }^{1}$ Neurobiological Psychiatry Unit, Department of Psychiatry, McGill University, Montréal, Quebec, Canada H3A 1A1, and ${ }^{2}$ Department of Psychiatry, Centre \\ de Recherche Fernand Seguin, Hôpital L.H. Lafontaine, Université de Montréal, Quebec, Canada H1N 3V2
}

\begin{abstract}
Preclinical and clinical studies show that cannabis modulates mood and possesses antidepressant-like properties, mediated by the agonistic activity of cannabinoids on central $C_{1}$ receptors $\left(C_{1} R s\right)$. The action of $C_{1} R$ agonists on the serotonin (5-HT) system, the major transmitter system involved in mood control and implicated in the mechanism of action of antidepressants, remains however poorly understood. In this study, we demonstrated that, at low doses, the $\mathrm{CB}_{1} \mathrm{R}$ agonist WIN55,212-2 [R(+)-[2,3-dihydro-5-methyl-3[(morpholinyl)]pyrrolo[1,2,3-de]-1,4-benzoxazinyl]-(1-naphthalenyl) methanone mesylate] exerts potent antidepressant-like properties in the rat forced-swim test (FST). This effect is $\mathrm{CB}_{1} \mathrm{R}$ dependent because it was blocked by the $\mathrm{CB}_{1} \mathrm{R}$ antagonist rimonabant and is 5 - $\mathrm{HT}$ mediated because it was abolished by pretreatment with the 5-HT-depleting agent parachlorophenylalanine. Then, using in vivo electrophysiology, we showed that low doses of WIN55,212-2 dose dependently enhanced dorsal raphe nucleus 5-HT neuronal activity through a $\mathrm{CB}_{1} \mathrm{R}$-dependent mechanism. Conversely, high doses of WIN55,212-2 were ineffective in the FST and decreased 5-HT neuronal activity through a $\mathrm{CB}_{1} \mathrm{R}$-independent mechanism. The $\mathrm{CB}_{1} \mathrm{R}$ agonist-induced enhancement of 5-HT neuronal activity was abolished by total or medial prefrontocortical, but not by lateral prefrontocortical, transection. Furthermore, 5-HT neuronal activity was enhanced by the local microinjection of WIN55,212-2 into the ventromedial prefrontal cortex ( $\mathrm{mPFCv}$ ) but not by the local microinjection of WIN55,212-2 into

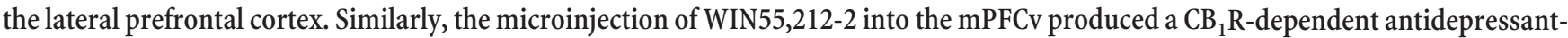
like effect in the FST. These results demonstrate that $\mathrm{CB}_{1} \mathrm{R}$ agonists possess antidepressant-like properties and modulate 5-HT neuronal activity via the mPFCv.
\end{abstract}

Key words: cannabinoid; $\mathrm{CB}_{1}$ receptor; serotonin; dorsal raphe nucleus; medial prefrontal cortex; depression; forced swim test

\section{Introduction}

Cannabis is the most widely used illicit drug (World Health Organization, 2006). Its major psychoactive constituent, $\Delta^{9}$ tetrahydrocannabinol, and other cannabinoids exhibit high affinity to brain $\mathrm{CB}_{1}$ receptors $\left(\mathrm{CB}_{1} \mathrm{Rs}\right) \cdot \mathrm{CB}_{1} \mathrm{R}$ activation modulates physiological, affective, cognitive, and psychomotor functions. Cannabis intoxication for instance engenders enhanced sociability, mood, and well-being, a condition described as "fatuous euphoria" (Iversen, 2003) whose physiological and subjective components are selectively blocked by the $\mathrm{CB}_{1} \mathrm{R}$ antagonist rimonabant (RIM) (Huestis et al., 2001).

Increased attention has been directed toward understanding

\footnotetext{
Received April 11, 2007; revised Sept. 11, 2007; accepted Sept. 11, 2007.

This work was supported by the Canadian Psychiatric Research Foundation, Fonds de la Recherche en Santé du Québec (G.G.), McGill University Health Center Research Institute, and McGill University Faculty of Medicine fellowships (F.R.B). We thank Dr. Daniele Piomelli (University of Irvine, Irvine, CA) for his critical feedback on the experimental design, and Claude Bouchard and Patrick Hattan for their assistance with histology. This work is dedicated in memory of Guy Debonnel and F. G. David, for their mentorship and friendship.

${ }^{\dagger}$ Deceased, November 4, 2006.

Correspondence should be addressed to Dr. Gabriella Gobbi, Neurobiological Psychiatry Unit, Department of Psychiatry, Research and Training Building, McGill University, 1033 Pine Avenue West, Montréal, Quebec, Canada H3A 1A1. E-mail: gabriella.gobbi@mcgill.ca.

DOI:10.1523/JNEUROSCI.1636-07.2007

Copyright $\odot 2007$ Society for Neuroscience $\quad 0270-6474 / 07 / 2711700-12 \$ 15.00 / 0$
}

the role of the endocannabinoid system in mood regulation. Clinical studies have reported benefits of cannabis on mood disorders (Ashton et al., 2005; Ware et al., 2005). Genetic (Haller et al., 2002, 2004; Martin et al., 2002) or pharmacological (Navarro et al., 1997; Deroche-Gamonet et al., 2001) $\mathrm{CB}_{1} \mathrm{R}$ blockade in murine models yields enhanced expression of depression/ anxiety-like behaviors. There are conflicting reports on the mood-related effects of $\mathrm{CB}_{1} \mathrm{R}$ agonists and antagonists/inverse agonists with regards to direction and potency of effects. Shearman et al. (2003) for example reported instead an antidepressantlike activity of the $\mathrm{CB}_{1} \mathrm{R}$ inverse agonist AM251 [N-1-(2,4dichlorophenyl)-5-(4-iodophenyl)-4-methyl- $N$-1-piperidinyl$1 \mathrm{H}$-pyrazole-3-carboxamide]. This apparent complexity has been attributed to dose-dependent bidirectional modulation, sensitivity of cannabimimetic responses to contextual conditions, and the kind of animal model and strain used (for review, see Viveros et al., 2005). Also, the possibility of interaction among receptor subtypes including a putative $\mathrm{CB}_{3} \mathrm{R}$ and vanilloid receptors, which has likewise been demonstrated operating in a plethora of cannabimimetic responses, may underlie ambivalent effects on mood modulation.

Despite evidence for the impact of $\mathrm{CB}_{1} \mathrm{R}$ activity on mood regulation, information on direct effects of cannabinoids on se- 
rotonergic neurotransmission remain meager. Serotonin (5HT) is the major neurotransmitter implicated in mood pathophysiology and in the mechanism of antidepresssant action (Blier and de Montigny, 1999). Several studies have nevertheless provided indications of functional cannabinoid-5-HT interaction. First, the dorsal raphe (DR), the principal source of forebrain 5-HT, expresses the endocannabinoid-degrading enzyme fatty acid amide hydrolase (FAAH) (Egertova et al., 1998, 2003), the $\mathrm{CB}_{1} \mathrm{R}$ in rats (Moldrich and Wenger, 2000), and $\mathrm{CB}_{1} \mathrm{R}$ mRNA in mice (Häring et al., 2007). Second, $\mathrm{CB}_{1} \mathrm{Rs}$ are abundantly expressed in the prefrontal cortex (PFC) (Marsicano and Lutz, 1999; Moldrich and Wenger, 2000), which sends excitatory afferents to the DR, coursing from the medial PFC (mPFC) (Jankowski and Sesack, 2004). Furthermore, upregulation in $\mathrm{PFC} \mathrm{CB}_{1} \mathrm{R}$ density, likely a compensatory feedback, was observed in suicidal depressives (Hungund et al., 2004). Imaging studies revealed that cannabis alters PFC regional cerebral blood flow and metabolic activity. The degree was correlated with subjective effects, and the pattern was consistent with $\mathrm{CB}_{1} \mathrm{R}$ localization (Volkow et al., 1991; Matthew et al., 2002). Third, $\mathrm{CB}_{1} \mathrm{R}$ agonism alters $5-\mathrm{HT}_{1 \mathrm{~A}}$ and $5 \mathrm{HT}_{2 \mathrm{~A}}$ receptor-mediated behavioral responses (Hill et al., 2006) and inhibits 5-HT reuptake in vitro (Banerjee et al., 1975; Johnson et al., 1976). In this study, we therefore aimed at determining whether the $\mathrm{CB}_{1} \mathrm{R}$ agonist WIN55,212-2 (WIN) $[R(+)$-[2,3-dihydro-5-methyl-3-[(morpholinyl)]pyrrolo [1,2,3-de]-1,4-benzoxazinyl]-(1-naphthalenyl) methanone mesylate] exhibits antidepressant-like effects in the forced swim test (FST), modulates 5 - $\mathrm{HT}$ activity through a $\mathrm{CB}_{1} \mathrm{R}$-mediated mechanism, and effects dose-dependent bidirectional modulations. Furthermore, using local microinfusions, we aimed to demonstrate that the $\mathrm{mPFC}$ is strongly involved in mediating these effects.

\section{Materials and Methods \\ Animals}

Adult male Sprague Dawley rats (Charles River, Saint-Constant, Quebec, Canada) weighing 280-350 g at the time of experiments were housed in pairs in standard polycarbonate cages. They were kept under standard laboratory conditions ( $12 \mathrm{~h}$ light/dark cycle, lights on at 7:30 A.M.; temperature at $20 \pm 2{ }^{\circ} \mathrm{C} ; 50-60 \%$ relative humidity). All rats had ad libitum access to food and water. One week before the start of experiments, rats were exposed to the testing environment and allowed to habituate to testing conditions. For rats that have undergone intracerebral cannulation, weights were monitored after surgery, and at least $4 \mathrm{~d}$ of postoperative recovery period was observed before additional tests were conducted. Drug administrations and electrophysiological and behavioral experiments were conducted between 2:00 P.M. and 10:00 P.M. All procedures were approved by the local institutional animal care and use committee and were in accordance to the ethical guidelines set by the Canadian Institutes of Health Research and the Society for Neuroscience.

\section{Drugs}

The $\mathrm{CB}_{1} \mathrm{R}$ agonist WIN55,212-2 (Sigma, Oakville, Ontario, Canada) was emulsified in Tween 80 (polyoxyethylene-sorbitan mono-oleate; Sigma) and further dissolved in saline with 5\% Tween 80 and 5\% poly(ethylene) glycol (Sigma). The WIN55,212-2 solution used for intracerebral microinfusions was dissolved in dimethylsulfoxide (DMSO) (Sigma) and vehicle (VEH) (1:2) because of the hydrophobic property of WIN55-212-2. The $\mathrm{CB}_{1} \mathrm{R}$ antagonist SR141716A/rimonabant [N-piperidino-5-(4-chlorophenyl)-1(2,4-dichlorophenyl)-4-methyl-pyrazolecarboxamide] (a kind gift from Dr. D. Piomelli, University of California, Irvine, CA) and the transient receptor potential vanilloid type 1 (TRPV1)/vanilloid receptor antagonist capsazepine (CPZ) (Tocris Bioscience, Ballwin, $\mathrm{MO}$ ) were initially dissolved in DMSO and further diluted (1:20) with saline containing 5\% Tween 80 and $5 \%$ poly(ethylene) glycol. Desipramine hydrochloride (DMI), parachlorophenylalanine (pCPA) (Sigma), and citalopram hydrobromide (CIT) (kindly provided by Lundbeck, Copenhagen, Denmark), were dissolved in
$0.9 \%$ physiological saline. The $\mathrm{pH}$ of vehicles and solutions used in the experiments was adjusted to 7.2 .

\section{Experiment 1: forced swim test}

The FST examines the dynamics of transition from an active (swimming and climbing) to a passive (immobility) mode of coping in an inescapable cylindrical water pool $(20 \mathrm{~cm}$ diameter, $50 \mathrm{~cm}$ high; $30 \mathrm{~cm}$ water depth, $25-27^{\circ} \mathrm{C}$ water temperature). During the course of the $5 \mathrm{~min}$ test swim session, an enhanced transition from activity to immobility resulting from a $15 \mathrm{~min}$ preexposure to the pool (preswim $24 \mathrm{~h}$ previously) has often been equated to learned behavioral despair (Porsolt et al., 1978). This enhancement of immobility is prevented by antidepressant treatment. Here, rats received $0.05,0.2,1.0$, or $2.0 \mathrm{mg} / \mathrm{kg}$ intraperitoneal injections of the potent $\mathrm{CB}_{1} \mathrm{R}$ agonist WIN55,212-2 23, 5, and $0.75 \mathrm{~h}$ before the test swim, modified after the protocol previously described by Page et al. (1999). A second cohort of rats was used to assess the effect of coadministering rimonabant with the dose of WIN55,212-2 that elicited the maximal antidepressant-like effect. A third cohort of rats was used to verify the role of 5-HT in mediating the effects of WIN55,212-2. Vehicle or pCPA (350 mg/kg, i.p., once daily), a selective inhibitor of the 5-HT synthesis precursory enzyme tryptophan hydroxylase that therefore depletes endogenous 5-HT, was administered 72 and $48 \mathrm{~h}$ before the swim test. WIN55,212-2 (0.2 mg/kg, i.p.) or vehicle were administered 23, 5, and $0.75 \mathrm{~h}$ before the swim test (modified after Page et al., 1999). Behavioral endpoints were analyzed by an automated tracking system equipped with infrared-sensitive cameras (Videotrack; Viewpoint Life Science, Montreal, Quebec, Canada). The predominant behaviors assessed were subsumed to one of three categories: immobility, in which the rat was making minimal movements to keep its head above water; swimming, in which the rat was engaged in average movements that cause it to move (usually horizontally) within the cylinder; and climbing (burst activity), in which forceful thrashing limb movements against the walls of the cylinder were observed. It has been shown that antidepressants with 5-HT-specific action selectively increase the duration of swimming, whereas those with a predominantly noradrenergic-specific activity increase those of climbing (Page et al., 1999). In all sessions, each animal was held on the neck and back, gently immersed in the pool hindlimbs first. They were removed from the pool using a plastic grid, then dried with a towel, and caged near a heat source. The FST is both sensitive and selective for clinically effective antidepressants, has been repeatedly validated, and is currently the most popular model for detecting antidepressant activity attributable to its simplicity, reliability, and high predictive validity (Lucki, 1997; Cryan et al., 2005). To control for false positives (increased activity in the FST of non-antidepressants), as has been consistently observed with psychostimulants (for review, see Cryan et al., $2005)$, a test for locomotor activity $(5 \mathrm{~min})$ in an open field $(80 \times 80 \mathrm{~cm})$, was also conducted, in which locomotor activity was operationalized as movement velocity (distance traveled in centimeters per minute).

\section{Experiment 2: electrophysiology}

In vivo extracellular single-unit recordings of presumed DR 5-HT neurons were performed to determine whether the antidepressant-like properties of WIN55,212-2 in the FST corresponded to a capacity to enhance 5 -HT neurotransmission. Recordings were conducted after repeated intraperitoneal administration following the FST protocol as well as after intravenous administration. All stereotaxic coordinates used in the succeeding experiments were based on the stereotaxic atlas of Paxinos and Watson (1986).

Preparation for electrophysiological experiments. Rats were anesthetized with chloral hydrate ( $400 \mathrm{mg} / \mathrm{kg}$, i.p.) and mounted in a stereotaxic frame (David Kopf Instruments, Tujunga, CA) with the skull positioned horizontally (incisor bar at -3.3). To maintain a full anesthetic state characterized by the absence of a nociceptive reaction to a paw/tail pinch and eyeblink response to pressure, chloral hydrate was continuously administered intraperitoneally at a dose of $50-70 \mathrm{mg} \cdot \mathrm{kg}^{-1} \cdot \mathrm{h}^{-1}$ using an infusion pump (Braintree Scientific, Braintree, MA). Body temperature was maintained at $37 \pm 0.5^{\circ} \mathrm{C}$ throughout the experiment using a rectal probe and a heating pad (Seabrook International, Seabrook, NH). Before electrophysiological recordings, a catheter was inserted into the lateral 
tail vein to facilitate systemic administration of drugs. Extracellular single-unit recordings were performed using single-barreled glass micropipettes pulled from $2 \mathrm{~mm}$ Stoelting (Wood Dale, IL) capillary glass on a Narashige (Tokyo, Japan) PE-21 pipette puller and preloaded with fiberglass strands to promote capillary filling with 2\% Pontamine Sky Blue dye in sodium acetate $(0.5 \mathrm{M}, \mathrm{pH} 7.5)$. The micropipette tips were broken down to diameters of 1-3 $\mu \mathrm{m}$. Electrode impedances ranged from 2 to $4 \mathrm{M} \Omega$. At the end of each experiment, the recording site was marked by iontophoretic ejection (5-10 $\mu \mathrm{A}$, negative current for $10 \mathrm{~min}$ ) of Pontamine Sky Blue for histological verification.

Single-unit extracellular recordings of DR 5-HT neurons. The doseresponse of putative 5 -HT neurons was assessed after single intravenous $(0.05-0.8 \mathrm{mg} / \mathrm{kg})$ and repeated intraperitoneal $(0.05-2 \mathrm{mg} / \mathrm{kg})$ administrations of WIN55,212-2. A burr hole was drilled on the midline, $1.2 \mathrm{~mm}$ anterior to interaural zero. Using a hydraulic micropositioner (model 650; David Kopf Instruments), the electrode was lowered into the DR. Putative 5-HT neurons were encountered immediately below the ventral border of the Sylvian aqueduct and abound between 5.0 and $6.5 \mathrm{~mm}$ ventral to the dura mater. These neurons under normal conditions were identified according to the following criteria: a slow $(0.1-4 \mathrm{~Hz})$ and prominently regular firing rate (coefficient of variation ranges from 0.12 to 0.87$)$ and a broad positive action potential $(0.8-3.5 \mathrm{~ms}$; $1.4 \mathrm{~ms}$ first positive and negative deflections) (Baraban and Aghajanian, 1980; Allers and Sharp, 2003). An inhibitory response to the $\mathrm{GABA}_{\mathrm{B}}$ agonist baclofen after intravenous drug administrations also confirmed that neurons were 5-HT because $\mathrm{GABA}_{\mathrm{B}}$ receptors are almost exclusively limited to 5-HT neurons in the DR (Wirtshafter and Sheppard, 2001).

5-HT burst activity. Burst activity pattern was analyzed based on the criteria of Gobbi et al. (2005), such that a train of at least two spikes with an onset defined by a maximum initial interspike interval of $20 \mathrm{~ms}$ within a regular low-frequency firing pattern was categorized as a burst. The longest interspike interval allowed within a burst was $40 \mathrm{~ms}$. In intraperitoneal experiments, two to four electrode descents were made to obtain a maximal sample of neurons across the rostrocaudal medial extent of the DR presumed richest in 5-HT neurons (Descarries et al., 1982). Recordings were also performed after coadministration of rimonabant $(1 \mathrm{mg} /$ $\mathrm{kg}$ ) injected intraperitoneally $10 \mathrm{~min}$ before the last WIN55,212-2 injection. Single-unit activity was recorded as discriminated action potentials amplified by a Tennelec (Oakridge, TN) TB3 MDA3 amplifier, postamplified and filtered by a Realistic 10 band frequency equalizer, digitalized by a CED1401 interface system (Cambridge Electronic Design, Cambridge, UK), processed on-line, and analyzed off-line by Spike2 software version 5.05 for Windows PC (Microsoft, Seattle, WA). Changes in neuronal firing pattern resulting from drug administrations were continuously monitored; the first $30 \mathrm{~s}$ immediately after drug injections were not considered to eliminate injection artifacts. Neurons were considered nonresponding if percentage change from baseline firing activity after drug administrations was $<10 \%$.

\section{Experiment 3: PFC transections}

To determine whether cannabinoid-induced modulation of DR 5-HT neurons originate in the PFC and are relayed via the descending corticoraphe fibers, systematic transections of the PFC-DR pathway were performed on anesthetized rats before electrophysiological recordings. For a total bilateral PFC transection (tPFC), a fine needle $(0.35 \mathrm{~mm}$ diameter) was initially positioned at $1 \mathrm{~mm}$ anterior to bregma and 0.8 $\mathrm{mm}$ left of the midline. It was lowered $6.8 \mathrm{~mm}$ from the dura mater, slowly slid leftward $5 \mathrm{~mm}$ from the midline $(0.5 \mathrm{~mm} / \mathrm{min})$, and then slowly retracted vertically using a micropositioner $(10 \mu \mathrm{m} / \mathrm{min})$. To avoid damaging the sinus, the needle was positioned $1.2 \mathrm{~mm}$ from the midline on the right hemisphere, lowered $6.8 \mathrm{~mm}$ at a $20^{\circ}$ angle, and then moved $5 \mathrm{~mm}$ rightward (modified after Diaz-Mataix et al., 2005). Selective transection of PFC subregions were performed by positioning the needle $2.5 \mathrm{~mm}$ anterior to bregma, lowered $6.8 \mathrm{~mm}$ from the dura mater, and moved $1.5 \mathrm{~mm}$ (on both sides) from the midline for an $\mathrm{mPFC}$ transection (areas transected included the dorsal peduncular, infralimbic, prelimbic $\mathrm{Cg} 3$, and cingulate $\mathrm{Cg} 1$ cortices) or from 1.5 to $5 \mathrm{~mm}$ for a transection of the lateral aspect of the prefrontal cortex (latPFC): mainly the lateral prefrontal/agranular insular, but also the frontal Fr2, Fr1, and
Fr3; the ventrolateral and lateral orbital cortices; and some parts of parietal area 1 (modified after Hajos et al., 1999). 5-HT single-unit recordings were conducted $1.5-2 \mathrm{~h}$ after transection.

\section{Experiment 4: combined intracerebral microinfusion and electrophysiology}

Experiment 4A: intracerebral microinfusion into the dorsal raphe nucleus. Anesthetized rats were implanted with a single guide cannula (22 gauge; Plastics One, Roanoke, VA) for intra-DR microinfusion of WIN55,212-2. The guide cannula was angled at $25^{\circ}$ from the vertical axis and aimed $1 \mathrm{~mm}$ above the DR to allow termination of the injector tip within the nucleus $(+1.2 \mathrm{~mm}$ from interaural zero, \pm 1.4 from midline, and $-6.0 \mathrm{~mm}$ from the dura mater). The cannula was fixed to the skull with the use of skull screws and dental acrylic. A $1.5-2 \mathrm{~h}$ postoperative interim period was allowed before the start of electrophysiological recordings (as described above in experiment 2). Once a stably firing 5-HT neuron was found and 1-3 min of baseline activity was established, microinfusion of either vehicle $(0.5 \mu \mathrm{l})$ or WIN55,212-2 (5 $\mu \mathrm{g} / 0.5 \mu \mathrm{l})$ was initiated and continuously delivered for $3 \mathrm{~min}$. Substances were infused into the DR via a 28 gauge stainless steel injector attached by polyethylene tubing to a $1 \mathrm{ml}$ syringe driven by a CMA 400 microdialysis syringe pump (CMA Microdialysis, Solma, Sweden). Changes in neuronal discharge pattern were continually monitored for up to $45 \mathrm{~min}$ after the cessation of microinfusion. The probability that results were confounded by random diffusion of solutions to neighboring structures was remote because, aside from the strictly controlled injection volume, the vehicle used was relatively viscous and lipophilic compared with conventional solvents. To mark the site of injection at the end of each experiment, a small volume ( $50 \mathrm{nl} /$ cannula) of Pontamine Sky Blue was infused via the same injector that was used for drug injections or was iontophoretically ejected from the recording pipette (see Fig. $5 C$ ).

Experiment 4B: intracerebral microinfusion into the prefrontal cortex, intra-mPFCv. Simultaneous bilateral microinfusion of WIN55,212-2 (5 $\mu \mathrm{g} / 0.5 \mu \mathrm{l}$ ) into the ventromedial subregions of the mPFC (mPFCv) (prelimbic-infralimbic cortices; $+2.2 \mathrm{~mm}$ from bregma, \pm 0.5 from midline, $-3.5 \mathrm{~mm}$ from the dura mater) was performed using a bilateral guide cannula (22 gauge, $1 \mathrm{~mm}$ center-to-center distance; Plastics One). The rest of the procedure was as described in the intra-DR microinfusion experiment (see above, experiment $4 \mathrm{~A}$ ).

Experiment 4C: intracerebral microinfusion into the prefrontal cortex, intra-latPFC. Simultaneous bilateral microinfusion of WIN55,212-2 (5 $\mu \mathrm{g} / 0.5 \mu \mathrm{l}$ ) into the latPFC (agranular insular cortex; $+3.2 \mathrm{~mm}$ from bregma, \pm 4.2 from midline, and $-4.2 \mathrm{~mm}$ from the dura mater) was performed with two single guide cannulas (22 gauge; Plastics One). The rest of the procedure was as described in the intra-DR microinfusion experiment (see above, experiment $4 \mathrm{~A}$ ).

Experiment 4D: intracerebral microinfusion into the prefrontal cortex, intra-mPFCv with PFC transection. To confirm whether the integrity of the mPFC-DR pathway is required for the modulatory effect of WIN55,212-2 on DR 5-HT neurons, a final negative control procedure was performed by combined microinfusion and electrophysiological techniques on PFC-transected rats. Anesthetized rats first underwent transection of the PFC ( $1 \mathrm{~mm}$ anterior to bregma; see above, experiment 3 ) and immediately implanted with a bilateral cannula into the mPFCv, as described previously ( $2.2 \mathrm{~mm}$ anterior to bregma; see above, experiment $4 \mathrm{~B}$ ) anterior to the transection lesion. Then, following the procedure used in experiment 4B, WIN55,212-2 was infused while performing single-unit recording on a DR 5-HT neuron.

\section{Experiment 5: intracerebral mPFCv microinfusion and FST}

Under Equithesin anesthesia $(3 \mathrm{ml} / \mathrm{kg}$ ) (1.96 g of sodium pentobarbital, $8.5 \mathrm{~g}$ of chloral hydrate, $4.25 \mathrm{~g}$ of $\mathrm{MgSO}_{4}$ hexahydrate, $60 \mathrm{ml}$ of propylene glycol, $20 \mathrm{ml}$ of ethanol, and $58 \mathrm{ml}$ of distilled water, adjusted to $200 \mathrm{ml}$ with distilled water), rats were mounted in a stereotaxic frame as described previously. Cannulation procedure was the same as in experiment $4 \mathrm{~B}$. After surgery, the incisions were stitched and applied with antiseptics. The cannulas were occluded with stainless steel wire stylets (Plastics One) to maintain patency. A postoperative recovery period of $8 \mathrm{~d}$ was allowed. Thereafter, cannulated rats were submitted to the FST 
(see above, experiment 1). A 15 min preswim test was conducted. The next day, rats were allowed to habituate to the testing room for $2 \mathrm{~h}$ before microinfusion. Then, WIN55,212-2 ( 1 or $5 \mu \mathrm{g}$ in $0.5 \mu \mathrm{l}$ of vehicle) or vehicle $(0.5 \mu \mathrm{l})$ was continuously delivered for $3 \mathrm{~min}$. In some cases, infusion of rimonabant [ $1 \mu \mathrm{g}$ (Caillé and Parsons, 2006) in $0.25 \mu \mathrm{l}$ of vehicle for $1.5 \mathrm{~min}$ ] was performed $1 \mathrm{~min}$ before infusion of WIN55,212-2 ( $1 \mu \mathrm{g}$ in $0.25 \mu \mathrm{l}$ of vehicle for $1.5 \mathrm{~min})$. In all groups, total infusion volume was $0.5 \mu \mathrm{l}$. The microinfusion connector assembly was left in place 4 more min to allow the drug solution to diffuse into the target structure (mPFCv). The rats were then placed in the cylindrical pool and subjected to the FST (5 min test swim recording).

\section{Histology}

Histological verification of the extent and selectivity of lesions imprinted by transections and cannula/microinjector trajectories were performed at the end of each experiment. The rats were deeply anesthetized (400 $\mathrm{mg} / \mathrm{kg}$ chloral hydrate, i.p.) and then perfused according to standard procedures (fixative, $4 \%$ paraformaldehyde with $0.1 \%$ glutaraldehyde). The brains were harvested and postfixed in $4 \%$ paraformaldehyde overnight and incubated in $30 \%$ sucrose for $2 \mathrm{~d}$. Adjacent series of $20-50 \mu \mathrm{A}$ brain slices within the vicinity of lesions were cut using a freezing microtome and stained with thionin acetate (Sigma) for light microscopic verification or stored in a cryoprotectant solution at $-20 \%$ until inspection.

\section{Statistical analyses}

SPSS (version 13; SPSS, Chicago, IL) was used to organize and statistically analyze data. All data were expressed as mean \pm SEM and were submitted to parametric tests (one-way or two-way ANOVA), followed by Student's $t$ test/Dunnett's test for post hoc comparisons. When assumptions of normality and variance homogeneity were not satisfied, nonparametric tests (Kruskal-Wallis or Friedman's tests for ANOVA, Mann-Whitney $U$ test for post hoc comparisons) were performed. Dunnett's post hoc test was used for comparing with baseline drug-induced changes in neuronal activity. Nonlinear curve fitting and the calculation of $\mathrm{ED}_{50}$ were performed using Microcal Software (Northampton, MA) Origin (version 7). Fisher's exact test was used to assess the differential response to $\mathrm{CB}_{1} \mathrm{R}$ blockade versus TRPV1 blockade after intravenous administrations of rimonabant and capsazepine. Statistical values reaching $p \leq 0.05$ were considered significant.

\section{Results}

\section{Effect of subchronic low and high doses of WIN55,212-2 in the FST}

To examine the possible dose-dependent effect of $\mathrm{CB}_{1} \mathrm{R}$ agonists on stress-coping behavior, we tested low and high doses of WIN55,212-2 in the FST. A low dose of WIN55,212-2 (0.2 mg/kg, i.p.) compared with vehicle elicited a significant decrease in total time spent in immobility (WIN at $0.2 \mathrm{mg} / \mathrm{kg}, 54.05 \pm 11.11$; VEH, $159.9 \pm 10.94 ;-66.2 \%, p<0.01$ ) (Fig. $1 A$ ) and a significant increase in total swimming duration (WIN at $0.2 \mathrm{mg} / \mathrm{kg}$, $220.08 \pm 10.39 ; \mathrm{VEH}, 128.86 \pm 10.72 ;+70.79 \%, p<0.01$ ) (Fig. $1 A$ ) but did not affect total climbing duration [WIN at $0.2 \mathrm{mg} / \mathrm{kg}$, $24.73 \pm 4.79 ; \mathrm{VEH}, 11.21 \pm 15$; no significant difference (NS)] (Fig. 1A). These effects were comparable with those produced by the clinically used selective serotonin reuptake inhibitor (SSRI) antidepressant citalopram ( $5 \mathrm{mg} / \mathrm{kg}$, i.p.; immobility, $47.8 \pm$ $15.25,-72.84 \%, p<0.01$ vs VEH; swimming, $218.83 \pm 25.4$, $+119.8 \%, p<0.01$ vs VEH; climbing, $33.33 \pm 13.78,+36.37 \%$, NS vs VEH) (Fig. 1A). Conversely, the selective norepinephrine reuptake inhibitor DMI (10 $\mathrm{mg} / \mathrm{kg}$, i.p.) elicited a decrease in total immobility duration $(30 \pm 6.57,-82.95 \%, p<0.01$ vs $\mathrm{VEH})$ and an increase in total climbing duration (142.01 \pm 19.6 , $+481.06 \%, p<0.01$ vs VEH) but not an increase in total swimming duration $(127.99 \pm 14.88,+28.56 \%$, NS vs VEH), confirming its primary action on noradrenergic transmission (Fig. $1 \mathrm{~A}$ ). The effects of the low dose of WIN55,212-2 on immobility and

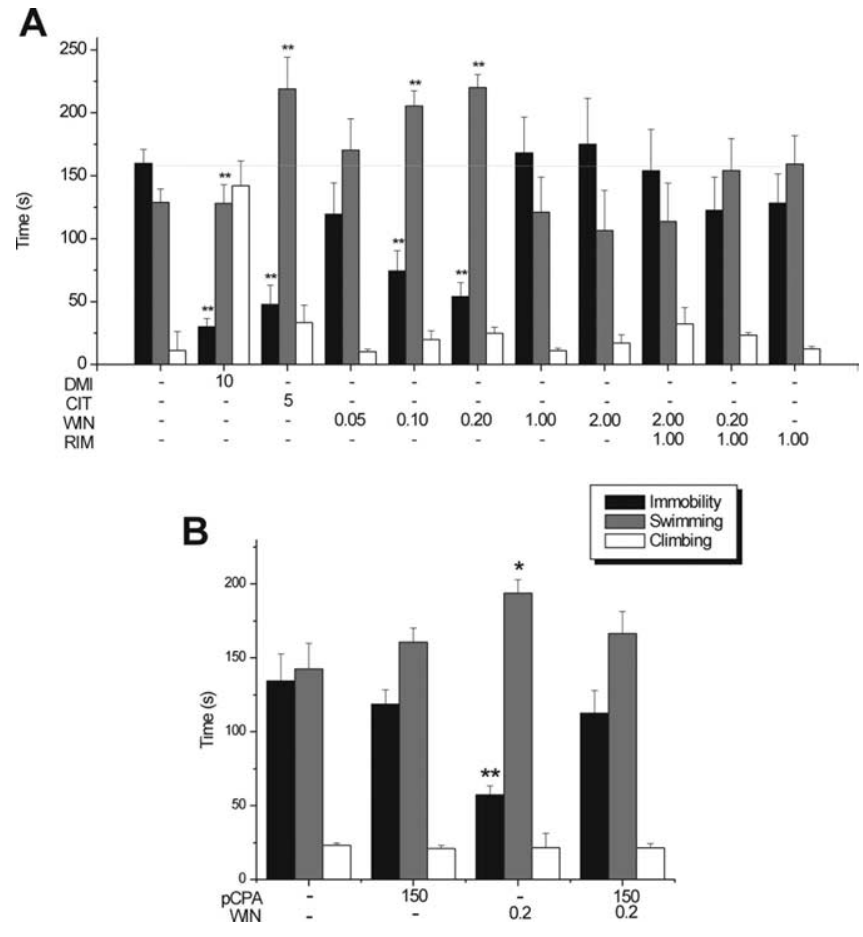

Figure 1. Antidepressant-like activity of WIN in the rat FST. A, Behavioral effects of intraperitoneally administered vehicle, CIT ( $5 \mathrm{mg} / \mathrm{kg}$, i.p.), DMI (10 mg/kg, i.p.), and WIN $(0.05,0.1,0.2,1.0$, and $2.0 \mathrm{mg} / \mathrm{kg}$, i.p.). Single injection of RIM (1 mg/kg, i.p.) $10 \mathrm{~min}$ before administration of a low dose of WIN $(0.2 \mathrm{mg} / \mathrm{kg}$, i.p.) blocked the antidepressantlike effect. Single injection of RIM ( $1 \mathrm{mg} / \mathrm{kg}$, i.p.) $10 \mathrm{~min}$ before administration of a high dose of WIN ( $2 \mathrm{mg} / \mathrm{kg}$, i.p.) did not modify the inert effect of WIN. Note that RIM by itself did not have any significant effect. $\boldsymbol{B}$, The antidepressant-like effect of WIN $(0.2 \mathrm{mg} / \mathrm{kg}$, i.p.) was abrogated by pretreatment with pCPA (150 mg/kg, i.p.) 72 and $48 \mathrm{~h}$ before pretest. Pretreatment of pCPA by itself did not have any significant effect. All treatments were administered 23,5 , and $0.75 \mathrm{~h}$ before test swim according to the method of Page et al. (1999). $n=8-15$ per treatment group. Bars represent mean \pm SEM total time of behaviors indicated. ${ }^{*} p<0.05$ or ${ }^{* *} p<0.01$ versus vehicle.

swimming behaviors were prevented by the coadministration of the $\mathrm{CB}_{1} \mathrm{R}$ antagonist RIM ( $1 \mathrm{mg} / \mathrm{kg}$, i.p.) (WIN at $0.2 \mathrm{mg} / \mathrm{kg}$ plus RIM at $1 \mathrm{mg} / \mathrm{kg}$, i.p.; immobility, $122.52 \pm 26.49,-23.38 \%$, NS vs VEH; swimming, $154.16 \pm 25.39,+19.63 \%$, NS vs VEH) (Fig. 1 A). A high dose of WIN55,212-2 (2 mg/kg, i.p.) did not shorten total immobility duration $(174.91 \pm 36.57,-0.91 \%$, NS vs VEH) and prolonged neither total swim duration (106.42 \pm 32.1 , $+6.89 \%$, NS vs VEH) nor total climbing duration $(17.16 \pm 6.5$, $-29.79 \%$, NS vs VEH) (Fig. 1A). This inert activity of the high dose of WIN55,212-2 was not changed during coapplication with RIM (WIN at $2.0 \mathrm{mg} / \mathrm{kg}$ plus RIM at $1 \mathrm{mg} / \mathrm{kg}$, i.p; immobility, $122.52 \pm 26.49$; swimming, $154.16 \pm 25.39$; or climbing, $23.4 \pm$ $2.0 \mathrm{vs} \mathrm{VEH}, \mathrm{NS}$ ) (Fig. $1 A$ ). RIM ( $1 \mathrm{mg} / \mathrm{kg}$, i.p.) did not induce any significant change in behavior (immobility, $128.32 \pm 23.26$; swimming, $159.34 \pm 22.48$; or climbing, $12.46 \pm 2.0 \mathrm{vs} \mathrm{VEH,} \mathrm{NS)}$ (Fig. 1A). The locomotor activity (movement velocity) of all drug-treated groups were not significantly different from that of the vehicle-treated group (CIT at $5 \mathrm{mg} / \mathrm{kg}, 433.24 \pm 19.52 ; \mathrm{DMI}$ at $10 \mathrm{mg} / \mathrm{kg}, 423.97 \pm 22.44 ; \mathrm{WIN}$ at $0.05 \mathrm{mg} / \mathrm{kg}, 423.21 \pm 30.12$; WIN at $0.10 \mathrm{mg} / \mathrm{kg}, 445.65 \pm 29.45 ;$ WIN at $0.2 \mathrm{mg} / \mathrm{kg}, 434.71 \pm$ 26.31; WIN at $2.0 \mathrm{mg} / \mathrm{kg}, 371.26 \pm 33.16$; WIN at $0.2 \mathrm{mg} / \mathrm{kg}$ plus $\mathrm{RIM}$ at $1 \mathrm{mg} / \mathrm{kg}, 476.82 \pm 21.46$; WIN at $2.0 \mathrm{mg} / \mathrm{kg}$ plus RIM at 1 $\mathrm{mg} / \mathrm{kg}, 382.12 \pm 37.26$; or RIM at $1 \mathrm{mg} / \mathrm{kg}, 399.92 \pm 22.50$, NS vs $\mathrm{VEH}, 433.23 \pm 24.21$ ). 
Effect of pCPA pretreatment on WIN55,212-2 antidepressantlike activity in the FST

Because the activity of the low dose of WIN55,212-2 in the FST was similar to that of the SSRI citalopram, we tested whether this antidepressant-like activity was via a main action on 5-HT transmission as observed with SSRIs (Page et al., 1999). When injected with the low dose of WIN55,212-2, rats pretreated with the 5-HT-depleting agent pCPA expressed neither increased swimming behavior (pCPA plus WIN at $0.2 \mathrm{mg} / \mathrm{kg}$, i.p., $166.35 \pm$ 15.06 vs VEH plus VEH, $142.54 \pm 17.2$, NS) (Fig. $1 B$ ) nor decreased immobility (pCPA plus WIN at $0.2 \mathrm{mg} / \mathrm{kg}$, i.p., $112.54 \pm$ 15.35 vs VEH plus VEH, $134.34 \pm 18.3$, NS) (Fig. $1 B$ ). Pretreatment of pCPA alone did not induce any effect significantly different from vehicle pretreatment (pCPA plus VEH; immobility, $118.57 \pm 9.72$; swimming, $160.6 \pm 9.65$; or climbing, $20.93 \pm$ 2.24 vs VEH plus VEH, NS) (Fig. $1 B$ ).

Effect of subchronic intraperitoneal doses of WIN55,212-2 on 5-HT single-unit activity

To test whether antidepressant-like behavioral effects of WIN55,212-2 in the FST were paralleled by enhanced 5-HT neuronal firing activity, we performed in vivo extracellular recordings of presumed 5-HT neurons following the same treatment schedule as in the FST. WIN55,212-2 was administered 23, 5, and $0.75 \mathrm{~h}$ before electrophysiological recordings. In some animals, RIM was injected intraperitoneally $10 \mathrm{~min}$ before the third administration of $0.2 \mathrm{mg} / \mathrm{kg}$ WIN55,212-2. Mean spontaneous firing rate of 5-HT neurons showed a biphasic response profile after incremental doses of WIN55,212-2. One-way ANOVA revealed a dose-dependent increase with lower doses of WIN55,212-2 (VEH, $1.14 \pm 0.04 ; \mathrm{WIN}$ at $0.05 \mathrm{mg} / \mathrm{kg}, 1.35 \pm 0.11 ; \mathrm{WIN}$ at 0.1 $\mathrm{mg} / \mathrm{kg}, 1.88 \pm 0.15 ; \mathrm{WIN}$ at $0.2 \mathrm{mg} / \mathrm{kg}, 2.58 \pm 0.25 ; F_{(3,203)}=$ 10.97; $p<0.01$ ) (Fig. $2 A$ ), and the coadministration of RIM prevented this increase. A dose of $0.2 \mathrm{mg} / \mathrm{kg}$ WIN55,212-2 yielded a maximal $126.32 \%$ increase in neuronal activity. Conversely, a high dose of WIN55,212-2 (2.0 mg/kg) yielded a significant decrease compared with vehicle (WIN at $2.0 \mathrm{mg} / \mathrm{kg}, 0.41 \pm$ $0.11,-64 \%, p<0.01$ vs VEH) (Fig. $2 A$ ). We also calculated the mean number of neurons per electrode descent, which served as an indirect measure of spontaneously active neurons (Gobbi et al., 2007). Compared with vehicle injections (VEH, $3.75 \pm 0.16$ ), there were $28 \%$ more spontaneously active 5 -HT neurons after treatment with $0.1 \mathrm{mg} / \mathrm{kg}$ WIN55,212-2 (4.8 $\pm 0.39, p<0.05)$ and $33.33 \%$ more active neurons with $0.2 \mathrm{mg} / \mathrm{kg}$ WIN55,212-2 $(5.0 \pm 0.46, p<0.01)$, whereas a high dose of WIN55,212-2 had fewer active neurons than the control (WIN at $2.0 \mathrm{mg} / \mathrm{kg}, 1.92 \pm$ $0.39,-48.8 \%, p<0.01)$. The number of spontaneously active neurons in rats treated with a low dose of WIN55,212-2 (0.2 $\mathrm{mg} / \mathrm{kg}$ ) coapplied with RIM $(1.0 \mathrm{mg} / \mathrm{kg})$ did not significantly differ from those treated with the vehicle (Fig. 2B).

\section{Effects of a single intravenous administration of low doses of} WIN55,212-2 on 5-HT firing activity

To appraise whether the $\mathrm{CB}_{1} \mathrm{R}$ agonist WIN55,212-2 rapidly influences 5-HT neurotransmission, we measured the spontaneous single-unit firing activity of DR 5-HT neurons after cumulative intravenous administration of WIN55,212-2. Incremental doses of WIN55,212-2 (0.05-0.2 mg/kg) evoked a dose-dependent increase in 5-HT unit firing activity $\left(F_{(3,62)}=4.64, p<0.01\right.$, oneway ANOVA; VEH, $1.04 \pm 0.10 \mathrm{~Hz}$; WIN at $0.05 \mathrm{mg} / \mathrm{kg}, 1.17 \pm$ $0.28 \mathrm{~Hz}$; WIN at $0.1 \mathrm{mg} / \mathrm{kg}, 1.61 \pm 0.37$; WIN at $0.2 \mathrm{mg} / \mathrm{kg}$, $2.04 \pm 0.27$ ) (Fig. $3 E$ ), which was half-maximal $\left(\mathrm{ED}_{50}\right)$ at a dose of $0.1 \mathrm{mg} / \mathrm{kg}$ and was not blocked by capsazepine $(20 \mu \mathrm{g} / \mathrm{kg}$, i.v. $)$
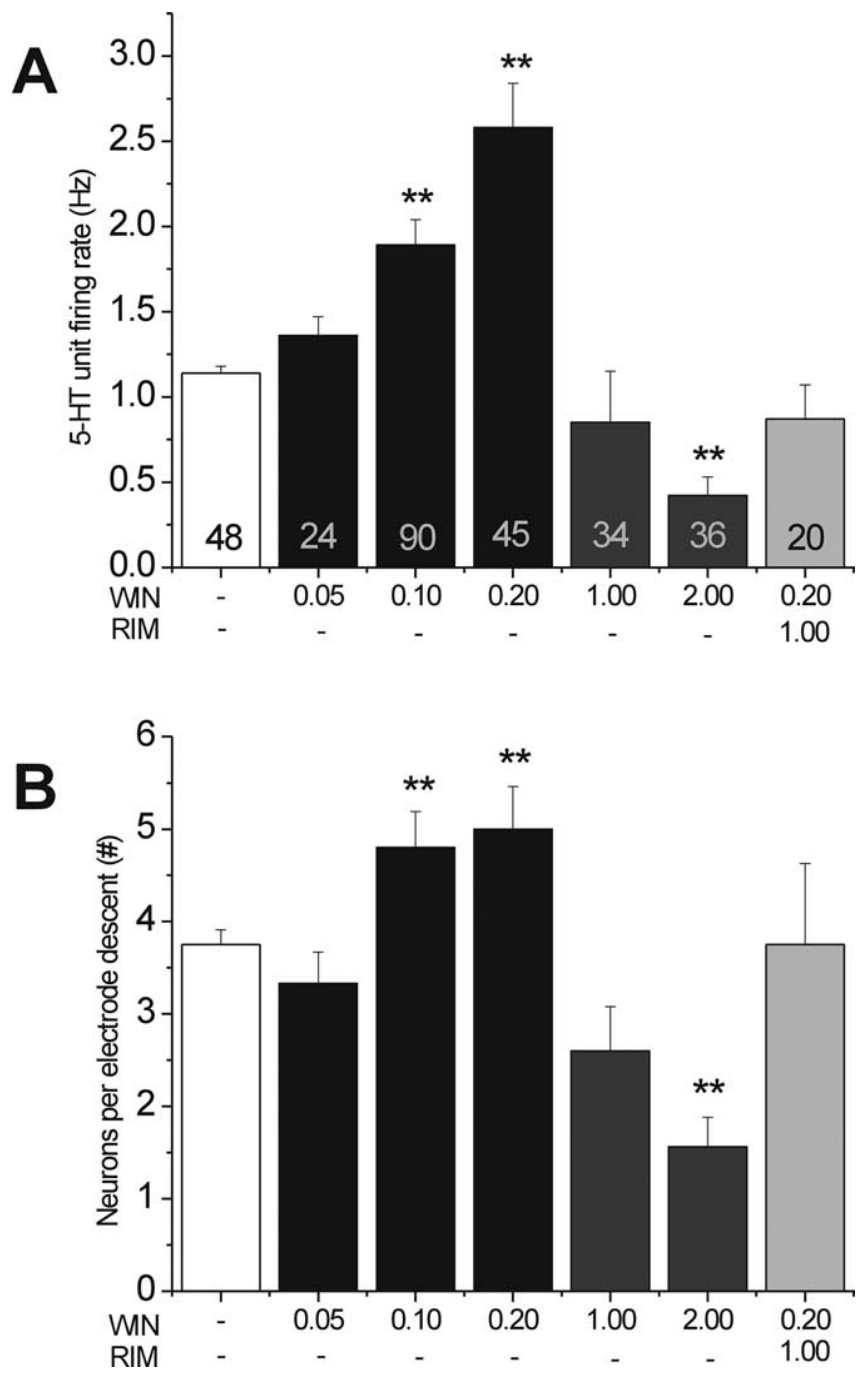

Figure 2. Effect of intraperitoneal administration of WIN on DR 5-HT neurons. $A$, Effect of WIN on 5-HT neuronal firing activity. WIN $(0.05-2.0 \mathrm{mg} / \mathrm{kg}$, i.p.) was administered 23,5 , and $0.75 \mathrm{~h}$ before electrophysiological recordings. Coapplication of RIM (1 mg/kg, i.p.) $10 \mathrm{~min}$ before WIN $(0.2 \mathrm{mg} / \mathrm{kg}$, i.p.) blocked the increase in spontaneous 5-HT single-unit firing activity. $\boldsymbol{B}$, Effect of WIN on the number of spontaneously active 5 -HT neurons. The number of spontaneously active neurons was calculated as the number of recorded 5 -HT neurons per electrode descent in each treatment group. Values at the base of each column in $\boldsymbol{A}$ denote the number of 5 -HT neurons recorded. Bars represent mean \pm SEM values. ${ }^{* *} p<0.01$ versus vehicle.

but was blocked by RIM ( $1 \mathrm{mg} / \mathrm{kg}$, i.v. ) in $100 \%$ of neurons tested $(n=4$; Fisher's test, $p=0.01)$ (Fig. 3A). WIN55,212-2 treatment also increased burst activity, a pattern of neural activity that is associated with enhanced 5-HT release in postsynaptic regions (Gartside et al., 2000), as well as antidepressant-like activity (Gobbi et al., 2005). The maximal increase in burst frequency from baseline (percentage recorded spikes contained in bursts) was recorded at $0.2 \mathrm{mg} / \mathrm{kg}(\mathrm{VEH}, 3.71 \pm 1.16 \%$; WIN at 0.05 $\mathrm{mg} / \mathrm{kg}, 8.85 \pm 3.59 \%$; WIN at $0.1 \mathrm{mg} / \mathrm{kg}, 9.61 \pm 3.15 \%$; WIN at $0.2 \mathrm{mg} / \mathrm{kg}, 12.51 \pm 4.07 ; \chi_{(3)}^{2}=12.56 ; p<0.01$, Kruskal-Wallis test) (Fig. 3F, top). The maximal increase in the mean number of spikes in a burst was $324 \%$ occurring at $0.2 \mathrm{mg} / \mathrm{kg}$ (VEH, $0.63 \pm$ $0.13 ; \mathrm{WIN}$ at $0.05 \mathrm{mg} / \mathrm{kg}, 1.23 \pm 0.42 ;$ WIN at $0.1 \mathrm{mg} / \mathrm{kg}, 1.28 \pm$ $0.32 ; \mathrm{WIN}$ at $0.2 \mathrm{mg} / \mathrm{kg}, 2.67 \pm 1.3 ; \chi_{(3)}^{2}=10.01 ; p<0.01$, Kruskal-Wallis test) (data not shown). Mean burst length was $82.25,235.35$, and $175.83 \%$ greater than baseline (vehicle) after incremental doses of $0.05,0.1$, and $0.2 \mathrm{mg} / \mathrm{kg}$ WIN55,212-2, respectively (VEH, $13.24 \pm 3.75 \mathrm{~ms}$; WIN at $0.05 \mathrm{mg} / \mathrm{kg}, 24.13 \pm$ 

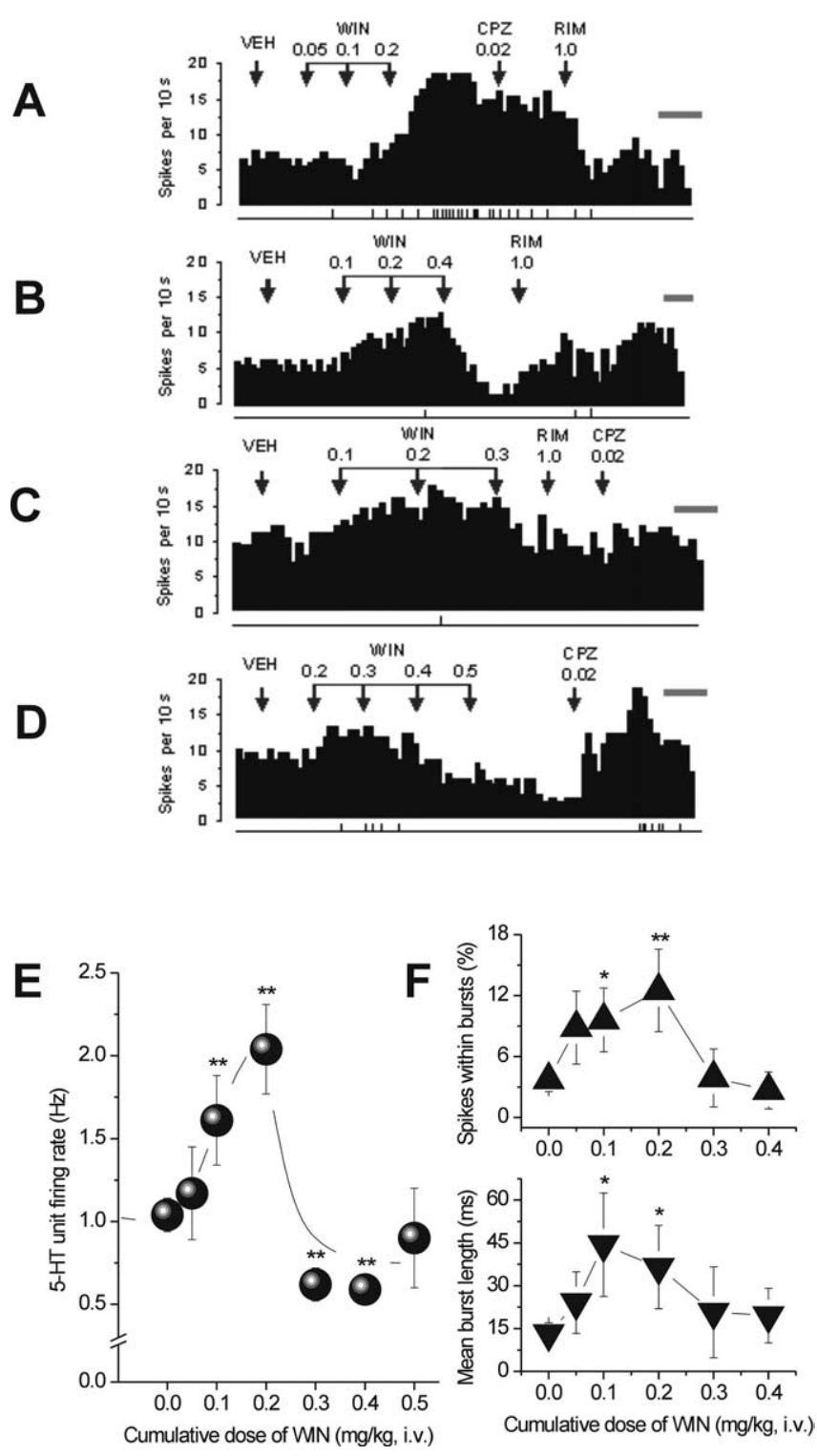

Figure 3. Effect of intravenous administration of cumulative doses of WIN on DR 5-HT neurons. $A-D$, Integrated firing rate histograms of 5 -HT neurons illustrating that low doses of WIN $(0.1-0.2 \mathrm{mg} / \mathrm{kg}$, i.v.) rapidly increased single-unit firing activity. $\boldsymbol{A}$, This effect was reversed by RIM (1.0 mg/kg, i.v.; $n=4)$ but not by CPZ $(0.02 \mathrm{mg} / \mathrm{kg}$, i.v.; $n=4)$. $B-D$, High dose of WIN $(0.30-0.50 \mathrm{mg} / \mathrm{kg}$, i.v.) rapidly decreased single-unit firing activity. This effect was reversed by CPZ $(0.02 \mathrm{mg} / \mathrm{kg}$, i.v.) in two of three neurons $(\boldsymbol{D})$ and partially reversed $(\boldsymbol{B})$ or unreversed $(\boldsymbol{C})$ by RIM (1 mg/kg, i.v.) in one and three neurons, respectively. 5-HT neuronal firing rate in each histogram is plotted as spikes per $10 \mathrm{~s}$. Calibration bar on right side of each histogram, $1 \mathrm{~min}$. The vertical lines depicted below each histogram represent the frequency of neuronal burst activity such that each tick corresponds to a burst discharge event. $\boldsymbol{E}$, WIN $(0.05-0.5 \mathrm{mg} / \mathrm{kg}$, i.v.) produced a biphasic response profile in 5 -HT single-unit activity. $\boldsymbol{F}$, Line graphs showing that cumulative doses of WIN modulated 5 -HT neuronal burst activity measured as percentage of spikes within bursts (top) and mean burst length (bottom). ${ }^{*} p<0.05$ or ${ }^{* *} p<0.01$ vs baseline (vehicle).

$10.79 \mathrm{~ms} ;$ WIN at $0.1 \mathrm{mg} / \mathrm{kg}, 44.4 \pm 18.1 \mathrm{~ms} ;$ WIN at $0.2 \mathrm{mg} / \mathrm{kg}$, $36.52 \pm 14.64 \mathrm{~ms} ; \chi_{(3)}^{2}=9.03 ; p<0.05$, Kruskal-Wallis test) (Fig. 3F, bottom). Among all neurons recorded, $66.67 \%(n=16)$ of 5 -HT neurons responded to increasing dose injections of WIN55,212-2, whereas $33.33 \%(n=8)$ of neurons were nonresponding. All responding and nonresponding neurons showed the same electrophysiological characteristics, were inhibited by baclofen, and were localized in the DR.
Effects of a single intravenous administration of high doses of WIN55,212-2 on 5-HT firing activity

Remarkably, cumulative doses higher than $0.2 \mathrm{mg} / \mathrm{kg}$ WIN55,212-2 injected intravenously generally produced a decline in neuronal excitation significant at both 0.3 and $0.4 \mathrm{mg} / \mathrm{kg}$ and achieved a maximal level $45 \%$ below baseline (vehicle) after $0.4 \mathrm{mg} / \mathrm{kg}$ WIN55,212-2 (VEH, $1.04 \pm 0.10 \mathrm{~Hz}$; WIN at 0.04 $\mathrm{mg} / \mathrm{kg}, 0.59 \pm 0.08 \mathrm{~Hz} ; F_{(1,45)}=6.7 ; p<0.01$ ) (Fig. $3 E$ ). A waning of stimulatory effects was also observed with burst activity: burst frequency (percentage of total number of recorded spikes; WIN at $0.3 \mathrm{mg} / \mathrm{kg}, 3.9 \pm 2.85 \%$; WIN at $0.4 \mathrm{mg} / \mathrm{kg}, 2.67 \pm 1.82 ; \mathrm{WIN}$ at $0.5 \mathrm{mg} / \mathrm{kg}, 10.51 \pm 6.21 \%$ ) (Fig. $3 F$, top), mean number of spikes in a burst (WIN at $0.3 \mathrm{mg} / \mathrm{kg}, 0.64 \pm 0.34$; WIN at 0.4 $\mathrm{mg} / \mathrm{kg}, 1.83 \pm 1.11 ; \mathrm{WIN}$ at $0.5 \mathrm{mg} / \mathrm{kg}, 1.5 \pm 0.5$ ) (data not shown), mean burst length (WIN at $0.3 \mathrm{mg} / \mathrm{kg}, 20.73 \pm 15.94 \mathrm{~ms}$; WIN at $0.4 \mathrm{mg} / \mathrm{kg}, 19.54 \pm 9.59 \mathrm{~ms}$; WIN at $0.5 \mathrm{mg} / \mathrm{kg}, 15.53 \pm$ $7.75 \mathrm{~ms}$ ) (Fig. $3 F$, bottom). The $\mathrm{CB}_{1} \mathrm{R}$ antagonist RIM ( $1 \mathrm{mg} / \mathrm{kg}$, i.v.) partially reversed this decline only in one of four neurons (Fig. 3B). Three neurons were nonresponsive (Fig. 3C). In two of three neurons tested, capsazepine reversed the decrease induced by high doses of WIN55,212-2 (Fig. 3D). This complex response pattern suggests that the $\mathrm{CB}_{1} \mathrm{R}$ may not be involved in the 5-HT effects induced by high doses of WIN55,212-2 (Fisher's test, $p=$ $0.57, \mathrm{NS}$ ). Neither RIM (RIM at $1 \mathrm{mg} / \mathrm{kg}$, i.v.) alone nor capsazepine (CPZ at $20 \mu \mathrm{g} / \mathrm{kg}$, i.v.) alone had a significant effect on 5 -HT single-unit firing activity $(\mathrm{VEH}, 1.3 \pm 0.33$; $\mathrm{CPZ}, 1.2 \pm$ $0.57, n=5$; RIM, $1.48 \pm 0.52, n=7$ ).

\section{5-HT single-unit activity after PFC transections}

DR 5-HT neurons receive important excitatory inputs from pyramidal (glutamatergic) cells of the PFC (Jankowski and Sesack, 2004). To verify whether cortical $\mathrm{CB}_{1} \mathrm{Rs}$ in the PFC or its subregions are essential in the control of DR 5-HT neurons by cannabinoids, rats were subjected to a tPFC, latPFC, or mPFC deafferentation by mechanical transection before 5-HT single-unit recordings. After tPFC transection, we observed that WIN55,212-2 failed to increase 5-HT single-unit firing activity at otherwise stimulatory doses in intact brains (tPFC transection: baseline, $1.46 \pm 0.39 \mathrm{~Hz}, n=7$; WIN at $0.05 \mathrm{mg} / \mathrm{kg}, 0.78 \pm 0.17$ $\mathrm{Hz}, n=6$; WIN at $0.1 \mathrm{mg} / \mathrm{kg}, 0.91 \pm 0.25 \mathrm{~Hz}, n=5$; WIN at 0.2 $\mathrm{mg} / \mathrm{kg}, 0.97 \pm 0.29 \mathrm{~Hz}, n=5 ;$ WIN at $0.3 \mathrm{mg} / \mathrm{kg}, 1.04 \pm 0.18 \mathrm{~Hz}$, $n=4$; WIN at $0.4 \mathrm{mg} / \mathrm{kg}, 0.97 \pm 0.17 \mathrm{~Hz}, n=4$; WIN at 0.5 $\mathrm{mg} / \mathrm{kg}, 1.10 \pm 0.15 \mathrm{~Hz}, n=4 ;$ WIN at $0.6 \mathrm{mg} / \mathrm{kg}, 1.31 \pm 0.40 \mathrm{~Hz}$, $n=3 ; p<0.01$ ) (Fig. $4 A$ ). We noted that, at doses higher than 0.6 $\mathrm{mg} / \mathrm{kg}$ intravenously, a moderate increase of firing activity can be elicited but was not sensitive to RIM (non- $\mathrm{CB}_{1} \mathrm{R}$-selective), which may indicate unspecific binding (data not shown). To pinpoint the specific subregion of the PFC that is critical in mediating the modulation of 5-HT single-unit activity, we compared transection of the mPFC with that of the latPFC. The response of 5-HT single units to the latPFC did not significantly differ from the control (baseline, $1.40 \pm 0.12 \mathrm{~Hz}, n=4$; WIN at $0.05 \mathrm{mg} / \mathrm{kg}$, $1.97 \pm 0.57 \mathrm{~Hz}, n=4$; WIN at $0.1 \mathrm{mg} / \mathrm{kg}, 2.18 \pm 0.59 \mathrm{~Hz}, n=4$; WIN at $0.2 \mathrm{mg} / \mathrm{kg}, 0.96 \pm 0.02 \mathrm{~Hz}, n=4$; NS vs control, betweengroups ANOVA) (Fig. 4A). On the contrary, mPFC transection produced an effect similar to tPFC transection and was significantly different from the control (baseline, $0.79 \pm 0.22 \mathrm{~Hz}, n=4$; $\mathrm{WIN}$ at $0.05 \mathrm{mg} / \mathrm{kg}, 0.79 \pm 0.20 \mathrm{~Hz}, n=4 ; \mathrm{WIN}$ at $0.1 \mathrm{mg} / \mathrm{kg}$, $0.81 \pm 0.23 \mathrm{~Hz}, n=4 ; \mathrm{WIN}$ at $0.2 \mathrm{mg} / \mathrm{kg}, 0.69 \pm 0.26 \mathrm{~Hz}, n=4$; WIN at $0.3 \mathrm{mg} / \mathrm{kg},-0.62 \pm 0.30 \mathrm{~Hz}, n=4 ;$ WIN at $0.4 \mathrm{mg} / \mathrm{kg}$, $0.71 \pm 0.21 \mathrm{~Hz}, n=4 ;$ WIN at $0.6 \mathrm{mg} / \mathrm{kg}, 1.03 \pm 0.33 \mathrm{~Hz}, n=4$; WIN at $0.7 \mathrm{mg} / \mathrm{kg}, 0.87 \pm 0.06, n=4 ; p<0.05$ vs control, between-groups ANOVA) (Fig. $4 A$ ), thus indicating that the me- 
A

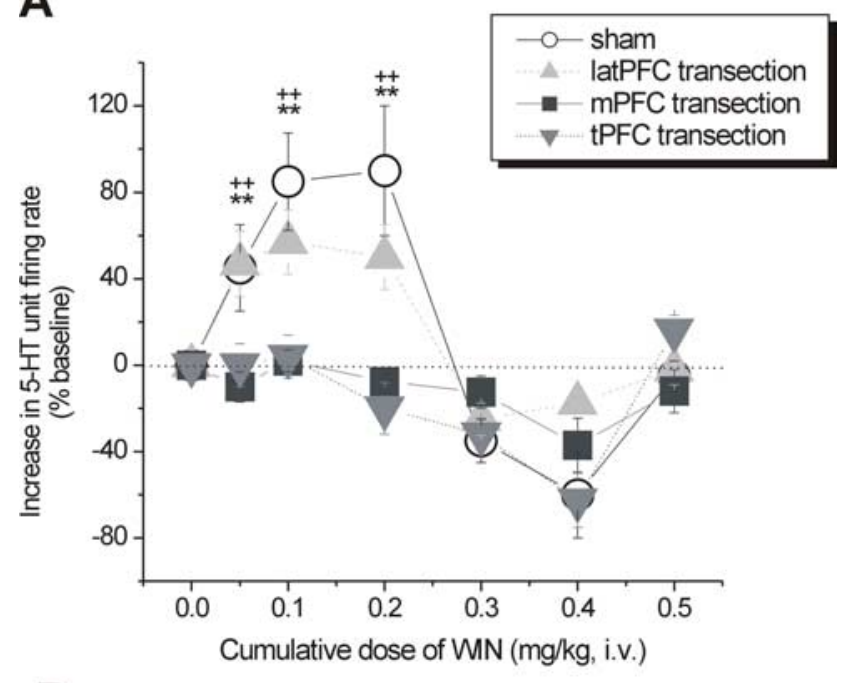

B
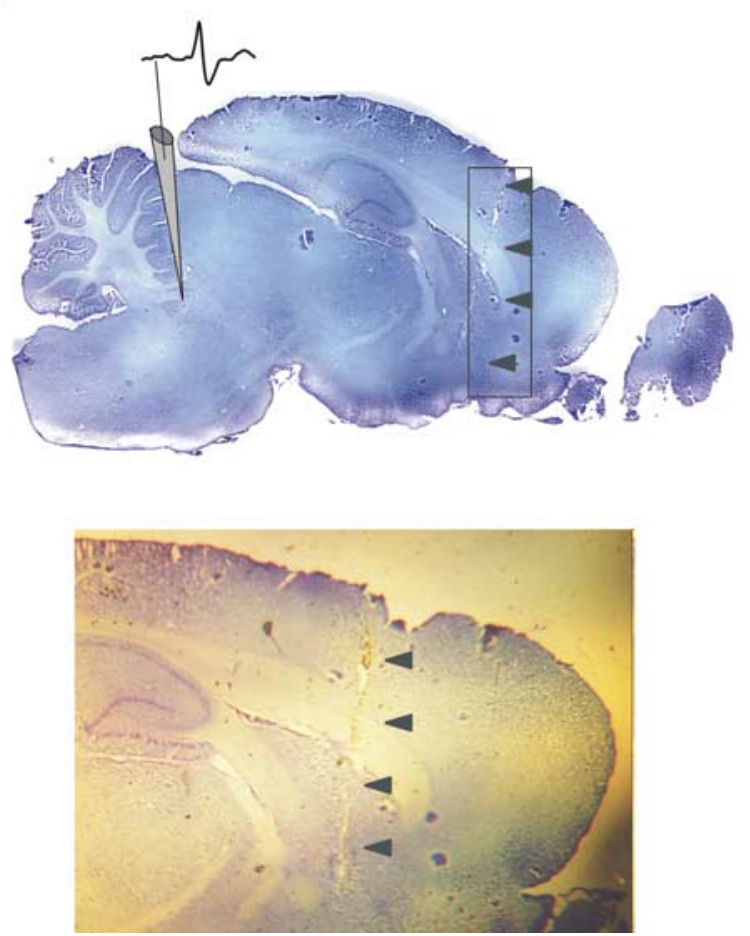

Figure 4. Effect of PFC transections on the modulation of DR5-HT neuronal activity by intravenous administration of WIN. $A$, Line graph showing the modulatory effect of cumulative doses of WIN $(0-0.5 \mathrm{mg} / \mathrm{kg})$ on $5-\mathrm{HT}$ single-unit firing activity after $\mathrm{PFCC}$ (shaded inverted triangles), ablation of $\mathrm{mPFC}$ (shaded squares), or latPFC (shaded upright triangles) subregions compared with shamexposed controls (open circles). tPFC and mPFC transections abrogated the excitatory response to low doses of WIN $(0.05-0.2 \mathrm{mg} / \mathrm{kg}$, i.v.), whereas latPFC transection did not significantly reduce the excitatory response to low doses of WIN $(0.05-0.2 \mathrm{mg} / \mathrm{kg}$, i.v.). $n=3-7$ animals per group. Values are expressed as mean \pm SEM of increase in 5 -HT unitfiring rate (percentage of baseline). ${ }^{* *} p<0.01$ $\mathrm{mPFC}$ transection versus control; ${ }^{++} p<0.01 \mathrm{tPFC}$ transection versus control. $\boldsymbol{B}$, Histological verification of the lesion left by atPFCtransection. Gray rectangle encompasses the anteroposterior range of all transections, and arrows point to an example of a cortical lesion trace on a midsagittal brain section ( $\sim 0.4 \mathrm{~mm}$ lateral to midline according to Paxinos and Watson, 1986). Shown is an illustrative depiction of the electrode placement and a typical action potential waveform of a putative $5-\mathrm{HT}$ neuron (top) and a closer inspection of the lesion trace (bottom).

dial, but not lateral, parts are responsible for the 5-HT firing activity enhancement by $\mathrm{CB}_{1} \mathrm{R}$ agonism. The transection procedure did not significantly modify the basal discharge rate of DR 5-HT neurons as was also observed by Hajos et al. (1999).

\section{Microinfusion of WIN55,212-2 into the mPFCv and DR: electrophysiology on 5-HT neurons}

To further localize the action of cannabinoids on 5-HT neurons, local microinfusion experiments were performed. Because the $\mathrm{CB}_{1} \mathrm{R}$ (Moldrich and Wenger, 2000) and $\mathrm{CB}_{1} \mathrm{R}$ mRNA (Häring et al., 2007) are present in the DR, it appeared reasonable to begin our attempt to localize the action of WIN55,212-2 within this nucleus, with the hypothesis that cannabinoid-induced 5-HT neuronal modulation occurs through local DR circuits. The microinfusion of WIN55,212-2 into the DR elicited a rapid increase $(63.64 \%)$ and decrease $(30 \%)$ in single-unit firing activity in one positive responder and one negative responder, respectively. The other two of four neurons recorded were nonresponders (Fig. $5 A, B)$.

The mPFCv is functionally associated with stress and coping mechanisms through the regulation of the DR (Amat et al., 2005). Therefore, we further assessed the impact of $\mathrm{CB}_{1} \mathrm{R}$ activation in the ventral prelimbic-infralimbic cortex (mPFCv) on 5-HT single-unit activity. To strengthen results obtained from the selective mPFC transection, we locally microinfused WIN55,212-2 into the $\mathrm{mPFCv}$ of both cortical hemispheres. Corroborating the results from the transections (experiment 3), a gradual increase in 5-HT single-unit firing activity was elicited in four of five $(80 \%)$ neurons recorded. This increase plateaued after $10-20$ min and was rapidly nullified by the injection of RIM $(1 \mathrm{mg} / \mathrm{kg}$, i.v.) (Fig. 6A). Furthermore, microinfusion of WIN55,212-2 into the same site in mPFC-transected brains $(n=2)$ (Fig. $6 C$ ) as well as into the latPFC $(n=2)$ (Fig. $6 D)$ did not elicit an increase in 5-HT single-unit activity in support of the necessity of the mPFC in cannabinoid-induced modulation of DR 5-HT neurons.

\section{Microinfusion of WIN55,212-2 into the mPFCv: behavior in the FST}

Because the results obtained from intracerebral WIN55,212-2 microinfusions with electrophysiology seemed to point to the $\mathrm{mPFCv}$ as a structure that plays an important role in cannabinoid-induced activation of DR 5-HT neurons, we therefore examined whether local bilateral microinfusion of WIN55,212-2 into the mPFCv is sufficient to alter stress-coping behaviors in the FST. Both microdoses of WIN55,212-2 used (1 and $5 \mu \mathrm{g}$ in $0.5 \mu \mathrm{l}$ of vehicle), compared with vehicle, produced a reduction of 47.43 and $36.24 \%$, respectively, in total immobility time (VEH, $142.92 \pm 14.29 \mathrm{~s} ;$ WIN at $1 \mu \mathrm{g}, 75.13 \pm 15.74 \mathrm{~s}$; WIN at $5 \mu \mathrm{g}, 90.12 \pm 20.93 \mathrm{~s} ; p<0.01 \mathrm{vs} \mathrm{VEH}$ ) (Fig. 7) and an enhancement of 38.78 and $32.31 \%$, respectively, in total swimming time (VEH, $141.09 \pm 12.97 \mathrm{~s}$; WIN at $1 \mu \mathrm{g}, 195.81 \pm 15.49$ s; WIN at $5 \mu \mathrm{g}, 186.68 \pm 18.84 \mathrm{~s} ; p<0.01$ vs VEH) (Fig. 7). There were no significant changes observed in climbing behavior $(\mathrm{VEH}$, $16.07 \pm 3.23 \mathrm{~s} ; \mathrm{WIN}$ at $1 \mu \mathrm{g}, 29.2 \pm 5.22 \mathrm{~s}$; WIN at $5 \mu \mathrm{g}, 21.50 \pm$ 7.43 s; NS vs VEH) (Fig. 7), implying that enhancement in noradrenergic transmission may not be as important as enhancement in serotonergic transmission in mediating the antidepressant-like effects of WIN55,212-2 in the FST. A microdose of RIM $(1 \mu \mathrm{g})$ that by itself did not induce any significant effect in the FST (immobility, $05.0 \pm 40$; swimming, $170.5 \pm$ 20.2; or climbing, $23.5 \pm 10$ vs VEH, NS) blocked the effect of 1 $\mu \mathrm{g}$ of WIN55,212-2 when microinfused 1 min before WIN55,212-2. In the open-field test, neither WIN55,212-2, RIM, nor RIM plus WIN55,212-2 induced a change in locomotor activity with the microdoses used, eliminating the possibility of a false positive in the FST (VEH, $422.93 \pm 41.38$; WIN at $1 \mu \mathrm{g}$, $400.31 \pm 50.86$; WIN at $5 \mu \mathrm{g}, 397.89 \pm 64.02$; RIM at $1 \mu \mathrm{g}$ plus WIN at $1 \mu \mathrm{g}, 431.43 \pm 42.12$; or RIM at $1 \mu \mathrm{g}, 455.26 \pm 31.9$ ). 
A

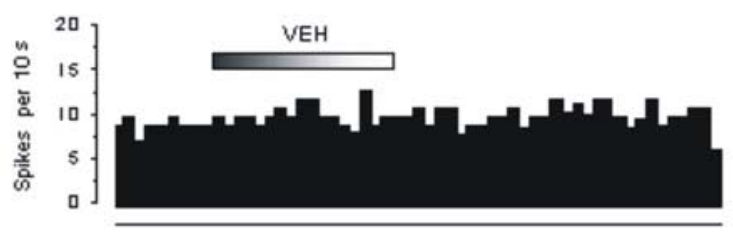

B

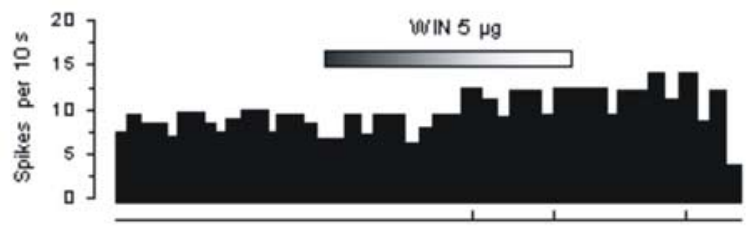

C
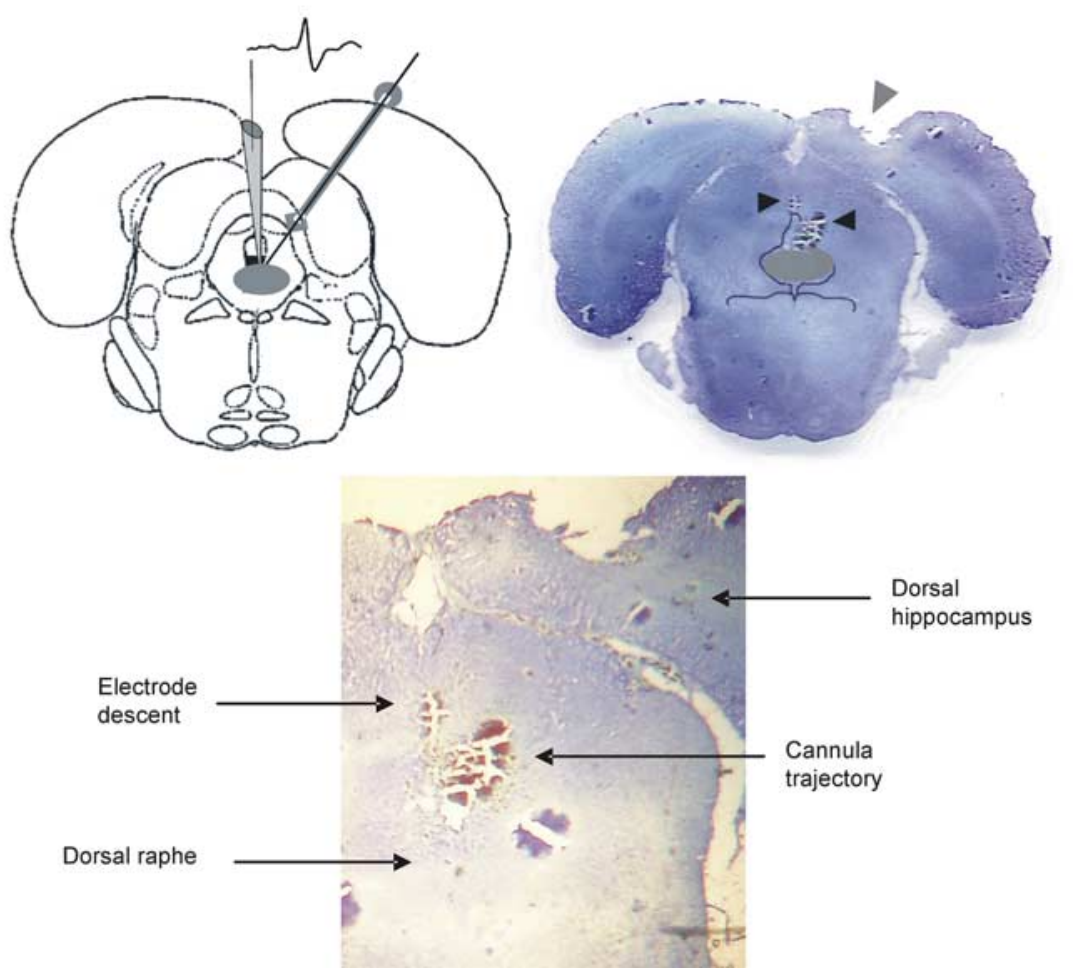

Figure 5. Effect of WIN microinfused into the DR. $A$, Integrated firing rate histogram of a 5 -HT neuron before and after intra-DR microinfusion of vehicle $(0.5 \mu \mathrm{l})$ ( $n=3$ neurons). $\boldsymbol{B}$, Integrated firing rate histogram of a 5 -HT neuron before and after intra-DR microinfusion of WIN ( $5 \mu \mathrm{g}$ in $0.5 \mu \mathrm{l}$ of vehicle) showing a slight increase in single-unit firing activity immediately after infusion observed in one of four neurons. Among the other three neurons, one showed a decrease whereas the other two did not respond at all. On each histogram, 5 -HT neuronal firing rate is plotted as spikes per $10 \mathrm{~s}$. Horizontal bar on top represents the time course of infusion, and vertical lines at the bottom represent the frequency of neuronal burst activity such that each tick corresponds to a burst event. C, Left, An illustrative depiction of the electrode descent into the DR (shaded gray area) and the trajectory of the microcannula based on the stereotaxic atlas of Paxinos and Watson (1986). Right, Histological verification of lesions imprinted by the electrode descent (left arrow) and of the microcannula (right arrow) on a coronal brain section ( $\sim 1.2$ anterior to interaural zero) showing the DR (shaded gray area). Bottom, Closer inspection of lesion traces.

\section{Discussion}

These results establish that low doses of a $\mathrm{CB}_{1} \mathrm{R}$ agonist elicit potent antidepressant-like behavior and enhance 5-HT neurotransmission, mediated by $\mathrm{CB}_{1} \mathrm{R}$ activation in the mPFCv. Conversely, high doses nullify antidepressant-like behavior and markedly attenuate 5-HT neurotransmission, an effect that appears to be instigated by a non- $\mathrm{CB}_{1} \mathrm{R}$ mechanism.

Similar to antidepressants selectively blocking 5-HT reuptake (SSRIs), the $\mathrm{CB}_{1} \mathrm{R}$ agonist WIN55,212-2 potently decreased immobility and increased swim behavior in the FST. This was attributed to direct $\mathrm{CB}_{1} \mathrm{R}$ activation that modulates 5-HT because it was blocked by the $\mathrm{CB}_{1} \mathrm{R}$ antagonist rimonabant and the 5-HT-depleting agent pCPA. Highlighting the role of $\mathrm{CB}_{1} \mathrm{R}$ in mood regulation, preclinical studies have indeed shown that its genetic and pharmacological blockade rendered animals more emotionally reactive and anxious (Haller et al., 2002, 2004; Martin et al., 2002), susceptible to chronic stress-induced anhedonia (Martin et al., 2002), and liable to impairments in hypothalamic-pituitary-adrenal regulation (Barna et al., 2004) reminiscent of neuroendocrine dysfunction observed in depression. Interestingly, $\mathrm{CB}_{1} \mathrm{R}$ knock-out mice presented impaired extinction of aversive memories (Marsicano et al., 2002), invoking the pathological hallmark of posttraumatic stress disorder, a condition possessing overlapping symptomatology and high rate of comorbidity with major depression (Vieweg et al., 2006). Antidepressant-like effects in the FST have also been reported previously with the endocannabinoid reuptake inhibitor AM404 [N-(4-hydroxyphenyl)arachidonamide] (Hill and Gorzalka, 2005) and the direct $\mathrm{CB}_{1} \mathrm{R}$ agonist HU-210 [3-(1,1-dimethylheptyl)-(-)-11-hydroxy- $\Delta^{8}$ tetrahydro-cannabinol] (Hill and Gorzalka, 2005; Jiang et al., 2005). Chronic HU-210 treatment was also found to drive hippocampal cell proliferation (Jiang et al., 2005), believed to be a downstream sequela of antidepressant treatment (Malberg et al., 2000). We recently demonstrated that the selective FAAH inhibitor URB597 cyclohexylcarbamic acid 3'carbamoylbiphenyl-3yl ester possesses antidepressant-like properties in the FST, tail suspension test (Gobbi et al., 2005), and chronic mild stress paradigm (Bortolato et al., 2007), in support of the concept that the endocannabinoid system may serve as target for depression therapy without the unwanted psychotropic effects of direct $\mathrm{CB}_{1} \mathrm{R}$ agonists. Moreover, perturbations in endocannabinoid signaling may very well be implicated in depression etiology, supported by the following. First, chronic unpredictable stress, used to model anhedonia, a core depression symptom, is associated with decreased endocannabinoid 2-arachidonoylglycerol in the rat hippocampus (Hill et al., 2005). Second, in humans, upregulation of $P F C C_{1} R$ in suicidal depressives may indicate an adaptive response to decreased endocannabinoids (Hungund et al., 2004). Third, randomized trials of the $\mathrm{CB}_{1} \mathrm{R}$ antagonist rimonabant for obesity management increased adverse effects of depression and anxiety (Bronander and Bloch, 2007).

We demonstrated that WIN55,212-2 dose dependently enhances the number, firing, and burst activity of spontaneously 


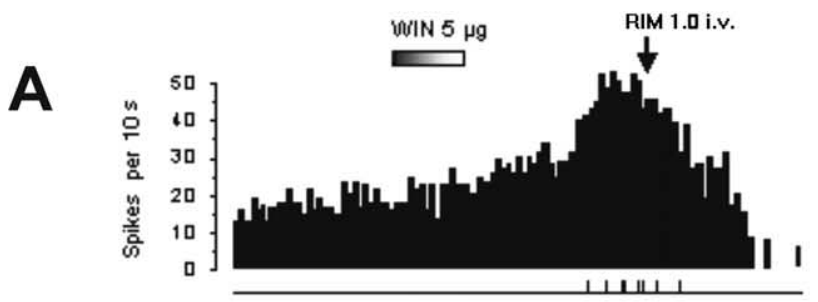

WIN 5 Hg

B

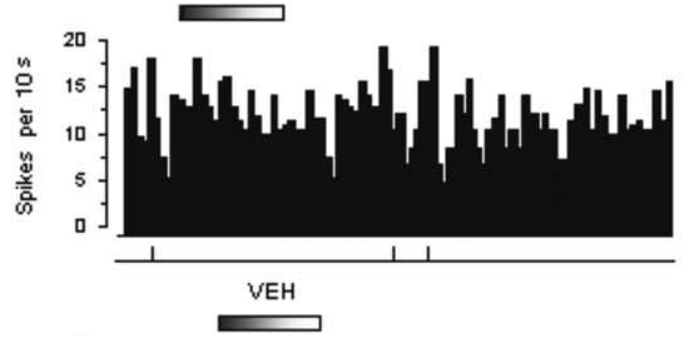

C

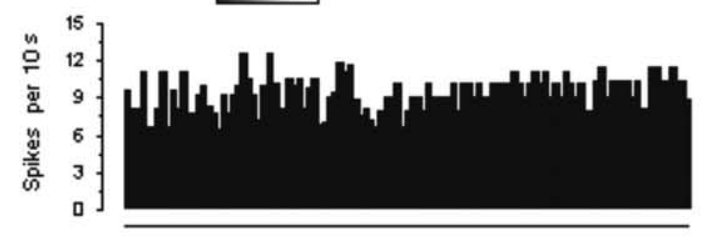

WIN $5 \mu \mathrm{g}$

D
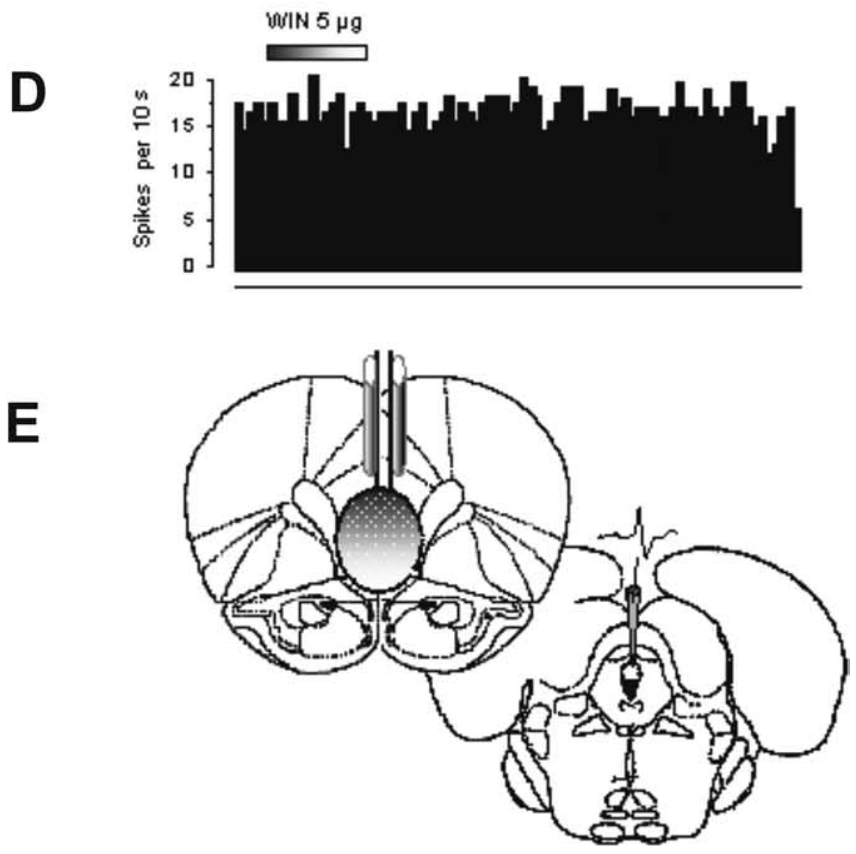

Figure 6. Effect of bilateral microinfusion of WIN into the mPFCv and latPFC on DR 5-HT neuronal activity. $\boldsymbol{A}$, Integrated firing rate histogram of a 5 -HT neuron showing a robust but slow-onset increase in single-unit activity after intra-mPFCv infusion of WIN ( $5 \mu \mathrm{g}$ in $0.5 \mu \mathrm{l}$ of vehicle) in four of five neurons. This effect was abrogated by RIM (1.0 mg/kg, i.v.). $\boldsymbol{B}$, Integrated firing rate histogram of a 5-HT neuron before and after intra-mPFCv infusion of WIN ( $5 \mu \mathrm{g}$ in 0.5 $\mu$ l of vehicle) showing an abolition of increased single-unit activity resulting from total prefrontocortical transection ( $n=2$ neurons). The microinfusion site was anterior to the transection lesion. $\mathbf{C}$, Integrated firing rate histogram of a 5-HT neuron before and after intra-mPFCv infusion of vehicle $(0.5 \mu \mathrm{l})$, showing no apparent effect on neuronal activity ( $n=4$ neurons). $\boldsymbol{D}$, Integrated firing rate histogram showing that intra-latPFC infusion of WIN (5 $\mu \mathrm{g}$ in $0.5 \mu \mathrm{l}$ of vehicle) did not produce an increase in 5 -HT single-unit activity ( $n=2$ neurons). On each histogram, 5-HT neuronal firing rate is plotted as spikes per $10 \mathrm{~s}$. Horizontal bar represents the time course of infusion, and vertical lines at the bottom represent the frequency of neuronal burst discharge such that each tick corresponds to a burst event. $\boldsymbol{E}$, Illustrative depiction of the placement of cannulas directed into the MPFCv (shaded region area, bregma +2.2 ) and the electrode descent into the dorsal raphe nucleus (interaural $0+1.2$ ), based on the stereotaxic atlas of Paxinos and Watson (1986).

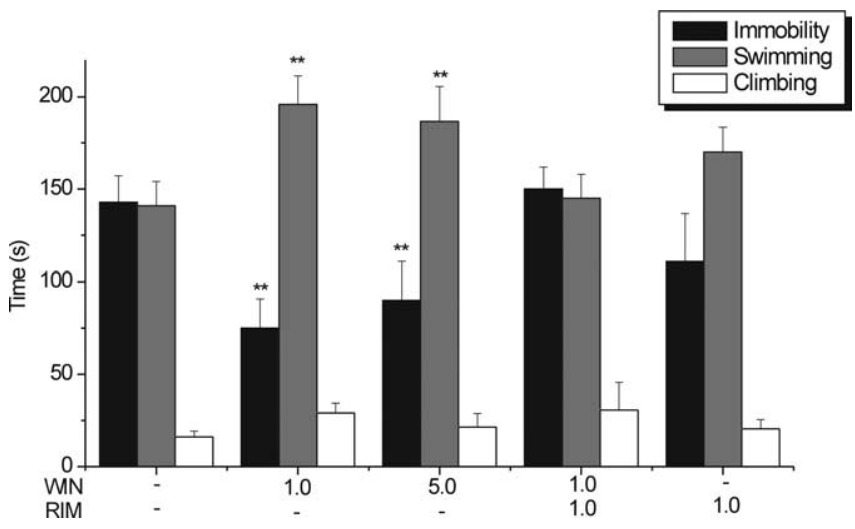

Figure 7. Behavioral effects of bilateral microinfusion of WIN and RIM into the mPFC $v$ in the ratFST. WIN ( 1 or $5 \mu \mathrm{g}$ in $0.5 \mu$ l of vehicle infused for $3 \mathrm{~min}$ ) administered $7-10 \mathrm{~min}$ before the FST increased total time spent swimming and decreased total time spent immobile. Bilateral microinfusion of RIM ( $1 \mu \mathrm{g}$ in $0.25 \mu$ l of vehicle for $1.5 \mathrm{~min}$ ) $1 \mathrm{~min}$ before microinfusion of WIN ( $1 \mu \mathrm{g}$ in $0.25 \mu \mathrm{l}$ for $1.5 \mathrm{~min}$ ) abrogated antidepressant-like effect. RIM ( $1 \mu \mathrm{g}$ in $0.5 \mu \mathrm{l}$ of vehicle for $3 \mathrm{~min}$ ) did not have any significant effect. $n=7-11$ animals per treatment group. ${ }^{* *} p<0.01$ versus vehicle.

active DR 5-HT neurons, corroborating microdialysis experiments that found increased synaptic 5-HT release in subcortical target regions (Fadda et al., 2006). We reported that elevating intrinsic anandamide through URB597 similarly elicited increased 5-HT activity (Gobbi et al., 2005). Both URB597 and WIN55,212-2 effects were $C_{1} R$ mediated because these were blocked by rimonabant. Noteworthy, the effects here observed with WIN55,212-2 were markedly different from those exerted by URB597 in at least two features. First, WIN55,212-2 elicited a rapid response as opposed to the 2 h delay with URB597; this difference might be ascribed to the kinetics of FAAH inhibition preceding anandamide-induced $\mathrm{CB}_{1} \mathrm{R}$ activation. Second, higher URB597 doses produced an enduring (plateau effect) excitation (Gobbi et al., 2005), whereas higher doses of WIN55,212-2 resulted in a rapid decline in excitation; this difference could be attributable to the fact that direct $\mathrm{CB}_{1} \mathrm{R}$ agonists activate wholebrain $\mathrm{CB}_{1} \mathrm{Rs}$, whereas FAAH inhibitors indirectly activate a subpopulation of these receptors colocalized with FAAH.

We identified that a $\mathrm{CB}_{1} \mathrm{R}$ subpopulation mediating 5 - $\mathrm{HT}$ excitatory response to WIN55,212-2 is localized in the $\mathrm{MPFC}$, the main source of cortical afferents to the DR (Hajos et al., 1999; Jankowski and Sesack, 2004). Convergent with results shown here, limbic 5-HT was enhanced after electrical stimulation of the mPFC but not of the latPFC (Juckel et al., 1999). Indeed, transecting $\mathrm{mPFC}$ efferents to the DR abolished the response of all recorded DR 5-HT neurons to the excitatory dose of WIN55,212-2. This was not observed after latPFC transection because of the absence of DR afferents from this area (Peyron et al., 1998). We surmise that the mPFCv particularly contained this receptor subpopulation because WIN55,212-2 bilaterally infused into this subregion markedly decreased FST immobility and increased basal discharge activity of DR 5-HT neurons. These effects were blocked by rimonabant.

The action of WIN55,212-2 may be explained by an enhanced feedforward excitatory input along mPFC-DR monosynaptic projections to 5-HT neurons possibly driven by disinhibiting pyramidal neurons (Fortin et al., 2004). Disinhibition was likely engaged by $\mathrm{CB}_{1} \mathrm{R}$ inhibitory control of cortical interneurons (Trettel and Levine, 2002), in agreement with the $\mathrm{G}_{\mathrm{i} / \mathrm{o}}$-proteinlinked transduction mechanism known to be associated with it and the resultant inhibition of voltage-sensitive calcium channels 
(Piomelli, 2003). This view is strengthened by the abundant perisomatic expression of $\mathrm{CB}_{1}$ Rs in neocortical and PFC interneurons (Tsou et al., 1998; Marsicano and Lutz, 1999). Also, cannabinoids have been shown to increase cortical excitatory transmission and net spiking probability of pyramidal neurons in vivo (Pistis et al., 2001; Fortin et al., 2004), consistent with a concurrent increment of basal glutamate levels and decrement of basal GABA levels in prefrontocortical microdialysis experiments observed in anesthetized (Pistis et al., 2002) and awake (Ferraro et al., 2001) rats, as well as in prefrontocortical in vitro culture (Ferraro et al., 2001; Tomasini et al., 2002).

The degree of controllability over stressors is processed by the $\mathrm{mPFCv}$, which in turn influences brainstem monoaminergic activity, particularly the DR (Amat et al., 2005, 2006; Maier et al., 2006). As such, it can be posited that the integrity of DR function in normosensitive states in relation to stress-coping and moodrelated behaviors relies on the efficiency of mPFCv pyramidal activity. The therapeutic relevance of increasing pyramidal transmission becomes explicit on consideration that simply brief exposures to uncontrollable stress already can inflict significant dendritic retraction of infralimbic pyramidal neurons and impair stress-coping and fear extinction in murines (Izquierdo et al., 2006). Incidentally, hyperactivating anandamide through FAAH knock-out, thereby enhancing intrinsic $\mathrm{CB}_{1} \mathrm{R}$ activity, has been observed to modulate PFC plasticity, significantly increasing dendritic spine density (Patel et al., 2007). This neuroplastic change is as well akin to an antidepressant-like effect on the mPFC observed after chronic antidepressant treatment (Sairanen et al., 2007).

Finally, we presented evidence that increasing WIN55,212-2 dose produces a bidirectional profile in the modulation of 5-HT neuronal firing and burst activity, as well as in FST antidepressant-like behavior. This effect mirrors classical biphasic/bidirectional biochemical, physiological, and psychopharmacological modulations by cannabinoids reported previously (for review, see Chaperon and Thiebot, 1999). Moreover, this bidirectional effect may explain the succession of euphoria and dysphoria during cannabis intoxication (American Psychiatric Association, 1994; Iversen, 2003), a phenomenon validated by neuropsychological measures (Ashton et al., 1981).

Although we point to $\mathrm{mPFCv} \mathrm{CB}_{1} \mathrm{R}$ as instrumental to WIN55,212-2-induced antidepressant-like effect and 5-HT activity enhancement, the 5-HT-decreasing effect appeared to be independent of $\mathrm{CB}_{1} \mathrm{R}$. The inert effect of high WIN55,212-2 doses in the FST and the decline in 5-HT excitation was generally nonsensitive to rimonabant. The TRPV1 antagonist capsazepine reversed the decline in 5-HT excitation induced by high WIN55,2212-2 doses. Interestingly, TRPV1 is expressed in both DR and PFC (Liapi and Wood, 2005) and is implicated in anxiety, conditioned fear, and hippocampal long-term potentiation (Marsch et al., 2007) and in schizophrenia (Chahl, 2007), whose negative symptoms overlap with depression. Second, we consider the possible role of the putative $\mathrm{CB}_{3} \mathrm{R}$ or a non- $\mathrm{CB}_{1}$ cannabinoid receptor possessing a lower affinity to WIN55,212-2 proposed to be present in glutamatergic terminals and thus in a position to inhibit the release of excitatory amino acids (Hajos and Freund, 2002). Indeed, a reduction of evoked glutamate-mediated synaptic currents in 5-HT neurons was observed in acute DR slice preparations (Haj-Dahmane and Shen, 2005). Third, $\mathrm{CB}_{1} \mathrm{R}$ agonists may differentially act on GABAergic and glutamatergic pathways as observed in the ventral tegmental area (VTA) (Melis et al., 2004; Riegel and Lupica, 2004). Interestingly, a dual receptor mechanism was also reported to occur in the amygdala (Pistis et al., 2004), periaqueductal gray (Maione et al., 2006), and hippocampus (Hajos and Freund, 2002).

Altogether, these data are highly suggestive of a significant role of the mPFCv in mood control and in DR 5-HT activity through $\mathrm{CB}_{1} \mathrm{R}$. We cannot, however, completely rule out the contributions of other brain regions and neurotransmitter systems that can act in concert with the mPFCv. The observed difference between systemic and intra-mPFCv WIN55,212-2 on the magnitude of FST effects may reflect extra-mPFCv contributions. $\mathrm{CB}_{1} \mathrm{R}$ agonists also modulate neuronal activity in various subcortical structures, e.g., the VTA (Diana et al., 1998), amygdala (Pistis et al., 2004), and locus ceruleus (Muntoni et al., 2006), all known to send afferents to the DR. Additional studies are underway to evaluate the influences of these areas on the activation of DR by cannabinoids.

Finally, this study confirms the emerging concept that the $\mathrm{CB}_{1} \mathrm{R}$ is an important new target in the development of antidepressant drugs. However, the challenge in the discovery of novel cannabinoid-derived agents lies in the development of agonists with selective antidepressant properties, and that minimize the unwanted psychotropic effects of cannabis.

\section{References}

Allers KA, Sharp T (2003) Neurochemical and anatomical identification of fast- and slow-firing neurons in the rat dorsal raphe nucleus using juxtacellular labeling methods in vivo. Neuroscience 122:193-204.

Amat J, Baratta MV, Paul E, Bland ST, Watkins LR, Maier SF (2005) Medial prefrontal cortex determines how stressor controllability affects behaviour and dorsal raphe nucleus. Nat Neurosci 8:365-371.

Amat J, Paul E, Zarza C, Watkins LR, Maier SF (2006) Previous experience with behavioral control over stress blocks the behavioral and dorsal raphe nucleus activating effects of later uncontrollable stress: role of ventral medial prefrontal cortex. J Neurosci 26:13264-13272.

American Psychiatric Association (1994) Diagnostic and statistical manual of mental disorders (DSM-IV-R), Ed 4. Washington, DC: American Psychiatric Association.

Ashton H, Golding J, Marsh VR, Millman JE, Thompson JW (1981) The seed and the soil: effect of dosage on the response to delta-9tetrahydrocannabinol in man. Br J Clin Pharmacol 12:705-720.

Ashton CH, Moore PB, Gallagher P, Young AH (2005) Cannabinoids in bipolar affective disorder: a review and discussion of their therapeutic potential. J Psychopharmacol 19:293-300.

Banerjee SP, Snyder SH, Mechoulam R (1975) Cannabinoids: influence on neurotransmitter uptake in rat brain synaptosomes. J Pharmacol Exp Ther 194:74-81.

Baraban JM, Aghajanian GK (1980) Suppression of firing activity of 5-HT neurons in the dorsal raphe by alpha-adrenoceptor antagonists. Neuropharmacology 19:355-363.

Barna I, Zelena D, Arszovszki AC, Ledent C (2004) The role of endogenous cannabinoids in the hypothalamo-pituitary-adrenal axis regulation: in vivo and in vitro studies in $\mathrm{CB}_{1}$ receptor knockout mice. Life Sci 75:2959-2970.

Blier P, de Montigny C (1999) Serotonin and drug-induced therapeutic responses in major depression, obsessive-compulsive and panic disorders. Neuropsychopharmacology 22:346-356.

Bortolato M, Mangieri RA, Fu J, Kim JH, Arguello O, Duranti A, Tontini A, Mor M, Tarzia G, Piomelli D (2007) Antidepressant-like activity of the fatty acid amide hydrolase inhibitor URB597 in a rat model of chronic mild stress. Biol Psychiatry, in press.

Bronander KA, Bloch MJ (2007) Potential role of the endocannabinoid receptor antagonist rimonabant in the management of cardiometabolic risk: a narrative review of available data. Vasc Health Risk Manag 3:181-190.

Caillé S, Parsons LH (2006) Cannabinoid modulation of opiate reinforcement through the ventral striatopallidal pathway. Neuropsychopharmacology 31:804-813.

Chahl LA (2007) TRP's: links to schizophrenia. Biochim Biophys Acta 1772:968-977. 
Chaperon F, Thiebot MH (1999) Behavioral effects of cannabinoid agents in animals. Crit Rev Neurobiol 13:243-281.

Cryan JF, Valentino RJ, Lucki I (2005) Assessing substrates underlying the behavioural effects of antidepressants using the modified rat forced swimming test. Neurosci Biobehav Rev 29:547-569.

Deroche-Gamonet V, Le Moal M, Piazza PV, Soubrie P (2001) SR141716A, a $\mathrm{CB}_{1}$ receptor antagonist, decreases the sensitivity to the reinforcing effects of electrical brain stimulation in rats. Psychopharmacology (Berl) 157:254-259.

Descarries L, Watkins KC, Garcia S, Beaudet A (1982) The serotonin neurons in nucleus raphe dorsalis of adult rat: a light and electron microscope radioautographic study. J Comp Neurol 207:239-254.

Diana M, Melis M, Gessa GL (1998) Increase in meso-prefrontal dopaminergic activity after stimulation of $\mathrm{CB}_{1}$ receptors by cannabinoids. Eur J Neurosci 10:2825-2830.

Diaz-Mataix L, Scorza MC, Bortolozzi A., Toth M, Celada P, Artigas F (2005) Involvement of $5-\mathrm{HT}_{1 \mathrm{~A}}$ receptors in prefrontal cortex in the modulation of dopaminergic activity: role in atypical antipsychotic action. J Neurosci 25:10831-10843.

Egertova M, Giang DK, Cravatt BF, Elphick MR (1998) A new perspective on cannabinoid signalling: complementary localization of fatty acid amide hydrolase and the $\mathrm{CB}_{1}$ receptor in rat brain. Proc Biol Sci 265:2081-2085.

Egertova M, Cravatt BF, Elphick MR (2003) Comparative analysis of fatty acid amide hydrolase and $\mathrm{CB}_{1}$ cannabinoid receptor expression in the mouse brain: evidence of a widespread role for fatty acid amide hydrolase in regulation of endocannabinoid signaling. Neuroscience 119:481-496.

Fadda P, Scherma M, Salis P, Mascia P, Fattore L, Fratta W (2006) Involvement of the $5-\mathrm{HT}_{1 \mathrm{~A}}$ serotonergic receptors in the anxiety-like effects induced by the $\mathrm{CB}_{1}$ receptor agonist WIN55,212-2. International Cannabinoid Research Society, 16th Annual Symposium on the Cannabinoids, Tihany, Hungary, June 24-28.

Ferraro L, Tomasini MC, Cassano T, Bebe W, Siniscalchi A, O'Connor WT, Magee P, Tanganelli S, Cuomo V, Antonelli T (2001) Cannabinoid receptor agonist WIN55,212-2 inhibits rat cortical dialysate gammaaminobutyric acid levels. J Neurosci Res 66:298-302.

Fortin DA, Trettel J, Levine ES (2004) Brief trains of action potentials enhance pyramidal neuron excitability vie endocannabinoid-mediated suppression of inhibition. J Neurophysiol 92:2105-2112.

Gartside SE, Hajos-Korcsok E, Bagdy E, Harsing Jr LG, Sharp T, Hajos M (2000) Neurochemical and electrophysiological studies on the functional significance of burst firing in serotonergic neurons. Neuroscience 98:295-300.

Gobbi G, Bambico FR, Mangieri R, Bortolato M, Campolongo P, Solinas M, Cassano T, Morgese MG, Debonnel G, Duranti A, Tontini A, Tarzia G, Mor M, Trezza V, Goldberg SR, Cuomo V, Piomelli D (2005) Antidepressant-like activity and modulation of brain monoaminergic transmission by blockade of anandamide hydrolysis. Proc Natl Acad Sci USA 102:18620-18625.

Gobbi G, Cassano T, Radja F, Morgese MG, Cuomo V, Santarelli L, Hen R, Blier P (2007) Neurokinin 1 receptor antagonism requires norepinephrine to increase serotonin function. Eur Neuropsychopharmacol 17:328-338.

Haj-Dahmane S, Shen RY (2005) The wake-promoting peptide orexin-B inhibits glutamatergic transmission to dorsal raphe nucleus serotonin neurons through retrograde endocannabinoid signaling. J Neurosci 25:896-905.

Hajos N, Freund TF (2002) Pharmacological separation of cannabinoid sensitive receptors on hippocampal excitatory and inhibitory fibers. Neuropharmacology 43:503-510.

Hajos M, Hajos-Korcsok E, Sharp T (1999) Role of the medial prefrontal cortex in 5-HT1A receptor-induced inhibition of 5-HT neuronal activity in the rat. Br J Pharmacol 126:1741-1750.

Haller J, Bakos N, Szirmay M, Ledent C, Freund TF (2002) The effects of genetic and pharmacological blockade of $\mathrm{CB}_{1}$ cannabinoid receptor on anxiety. Eur J Neurosci 16:1395-1398.

Haller J, Varga B, Ledent C, Barna I, Freund TF (2004) Context-dependent effects of $\mathrm{CB}_{1}$ cannabinoid gene disruption on anxiety-like and social behaviour in mice. Eur J Neurosci 19:1906-1912.

Häring M, Marsicano G, Lutz B, Monory K (2007) Identification of the cannabinoid receptor type 1 in serotonergic cells of raphe nuclei in mice. Neuroscience 146:1212-1219.
Hill MN, Gorzalka BB (2005) Pharmacological enhancement of cannabinoid $\mathrm{CB}_{1}$ receptor activity elicits an antidepressant-like response in the rat forced swim test. Eur Neuropsychopharmacol 15:593-599.

Hill MN, Patel S, Carrier EJ, Rademacher DJ, Ormerod BK, Hillard CJ, Gorzalka BB (2005) Downregulation of endocannabinoid signaling in the hippocampus following chronic unpredictable stress. Neuropsychopharmacology 30:508-515.

Hill MN, Sun JC, Tse MT, Gorzalka BB (2006) Altered responsiveness of serotonin receptor subtypes following long-term cannabinoid treatment. Int J Neuropsychopharmacol 9:277-286.

Huestis MA, Gorelick DA, Heishman SJ, Preston KL, Nelson RA, Moolchan ET, Frank RA (2001) Blockade of effects of smoked marijuana by the $\mathrm{CB}_{1}$-selective cannabinoid receptor antagonist SR141716. Arch Gen Psychiatry 58:322-328.

Hungund BL, Vinod KY, Kassir SA, Basavarajappa BS, Yalamanchili R, Cooper TB, Mann JJ, Arango V (2004) Upregulation of $\mathrm{CB}_{1}$ receptors and agonist-stimulated [35S]GTPgammaS binding in the prefrontal cortex of depressed suicide victims. Mol Psychiatry 9:184-190.

Iversen L (2003) Cannabis and the brain. Brain 126:1252-1270.

Izquierdo A, Wellman CL, Holmes A (2006) Brief uncontrollable stress causes dendriticretraction in infralimbic cortex and resistance to fear extinction in mice. J Neurosci 26:5733-5738.

Jankowski MP, Sesack SR (2004) Prefrontal cortical projections to the rat dorsal raphe nucleus: ultrastructural features and associations with serotonin and gamma-aminobutyric acid neurons. J Comp Neurol 468:518-529.

Jiang W, Zhang Y, Xiao L, Van Cleemput J, Ji SP, Bai G, Zhang X (2005) Cannabinoids promote embryonic and adult hippocampus neurogenesis and produce anxiolytic- and antidepressant-like effects. J Clin Invest 115:3104-3116.

Johnson KM, Ho BT, Dewey WL (1976) Effects of delta9-tetrahydrocannabinol on neurotransmitter accumulation and release mechanisms in rat forebrain synaptosomes. Life Sci 19:347-356.

Juckel G, Mendlin A, Jacobs BL (1999) Electrical stimulation of rat medial prefrontal cortex enhances forebrain serotonin output: implications for electroconvulsive therapy and transcranial magnetic stimulation in depression. Neuropsychopharmacology 21:391-398.

Liapi A, Wood JN (2005) Extensive co-localization and heteromultimer formation of the vanilloid receptor-like protein $\mathrm{TRPV}_{2}$ and the capsaicin receptor $\mathrm{TRPV}_{1}$ in the adult rat cerebral cortex. Eur J Neurosci 22:825-834.

Lucki I (1997) The forced swimming test as a model for core and component behavioural effects of antidepressant drugs. Behav Pharmacol 8:522-532.

Maier SF, Amat J, Baratta MV, Paul E, Watkins LR (2006) Behavioural control, the medial prefrontal cortex, and resilience. Dialogues Clin Neurosci 8:397-406.

Maione S, Bisogno T, de Novellis V, Palazzo E, Cristino L, Valenti M, Petrosino S, Guglielmotti V, Rossi F, Di Marzo V (2006) Elevation of endocannabinoid levels in the ventrolateral periaqueductal grey through inhibition of fatty acid amide hydrolase affects descending nociceptive pathways via both cannabinoid receptor type 1 and transient receptor potential vanilloid type-1 receptors. J Pharmacol Exp Ther 316:969-982.

Malberg JE, Eisch AJ, Nestler EJ, Duman RS (2000) Chronic antidepressant treatment increases neurogenesis in adult rat hippocampus. J Neurosci 20:9104-9110.

Marsch R, Foeller E, Rammes G, Bunck M, Kossl M, Holsboer F, Zieglgansberger W, Landgraf R, Lutz B, Wotjak CT (2007) Reduced anxiety, conditioned fear, and hippocampal long-term potentiation in transient receptor potential vanilloid type 1 receptor-deficient mice. J Neurosci 27:832-839.

Marsicano G, Lutz B (1999) Expression of the cannabinoid receptor $\mathrm{CB}_{1}$ in distinct neuronal subpopulations in the adult mouse forebrain. Eur J Neurosci 11:4213-4225.

Marsicano G, Wotjak CT, Azad SC, Bisogno T, Rammes G, Cascio MG, Hermann H, Tang J, Hofmann C, Zieglgansberger W, Di Marzo V, Lutz B (2002) The endogenous cannabinoid system controls extinction of aversive memories. Nature 418:530-534.

Martin M, Ledent C, Parmentier M, Maldonado R, Valverde O (2002) Involvement of $\mathrm{CB}_{1}$ cannabinoid receptors in emotional behaviour. Psychopharmacology (Berl) 159:379-387.

Matthew RJ, Wilson WH, Turkington TG, Hawk TC, Coleman RE, DeGrado 
TR, Provenzale J (2002) Time course of tetrahydrocannabinol-induced changes in regional cerebral blood flow measured with positron emission tomography. Psychiatry Res Neuroimaging 116:173-185.

Melis M, Pistis M, Pera S, Muntoni AL, Pillola G, Gessa GL (2004) Endocannabinoids mediate presynaptic inhibition of glutamatergic transmission in rat ventral tegmental area dopamine neurons through activation of $\mathrm{CB}_{1}$ receptors. J Neurosci 24:53-62.

Moldrich G, Wenger T (2000) Localization of the $\mathrm{CB}_{1}$ cannabinoid receptor in the rat brain: an immunohistochemical study. Peptides 21:1735-1742.

Muntoni AL, Pillolla G, Melis M, Perra S, Gessa GL, Pistis M (2006) Cannabinoids modulate spontaneous neuronal activity and evoked inhibition of locus coeruleus noradrenergic neurons. Eur J Neurosci 23:2385-2394.

Navarro M, Hernandez E, Muñoz RM, del Arco I, Villanua MA, Carrera MR, Rodriguez de Fonseca F (1997) Acute administration of the $\mathrm{CB}_{1}$ cannabinoid receptor antagonist SR141716A induces anxiety-like responses in the rat. NeuroReport 8:491-496.

Page ME, Detke MJ, Dalvi A, Kirby LG, Lucki I (1999) Serotonergic mediation of the effects of fluoxetine, but not desipramine, in the rat forced swimming test. Psychopharmacology (Berl) 147:162-167.

Patel S, Wang HD, Hillard CJ, Deutch AY (2007) Endocannabinoid signaling modulates dendritic spine density in prefrontal cortical pyramidal cells. International Cannabinoid Research Society, 17th Annual Symposium on the Cannabinoids, Saint-Sauveur, Quebec, Canada, June 26-30.

Paxinos G, Watson C (1986) The rat brain in stereotaxic coordinates. San Diego: Academic.

Peyron C, Petit JM, Rampon C, Jouvet M, Luppi PH (1998) Forebrain afferents to the rat dorsal raphe nucleus demonstrated by retrograde and anterograde tracing methods. Neuroscience 82:443-468.

Piomelli D (2003) The molecular logic of endocannabinoid signaling. Nat Rev Neurosci 4:873-884.

Pistis M, Porcu G, Melis M, Diana M, Gessa GL (2001) Effects of cannabinoids on prefrontal neuronal responses to ventral tegmental area stimulation. Eur J Neurosci 14:96-102.

Pistis M, Ferraro L, Pira L, Flore G, Tanganelli S, Gessa GL, Devoto P (2002) Delta(9)-tetrahydrocannabinol decreases extracellular GABA and increases extracellular glutamate and dopamine levels in the rat prefrontal cortex: an in vivo microdialysis study. Brain Res 948:155-158.

Pistis M, Perra S, Pillola G, Melis M, Gessa GL, Muntoni AL (2004) Cannabinoids modulate neuronal firing in the rat basolateral amygdala: evidence for $\mathrm{CB}$ - and non- $\mathrm{CB}_{1}$-mediated actions. Neuropharmacology 46:115-125.

Porsolt RD, Bertin A, Jalfre M (1978) “Behavioural despair" in rats and mice: strain differences and the effects of imipramine. Eur J Pharmacol 51:291-294.

Riegel AC, Lupica CR (2004) Independent presynaptic and postsynaptic mechanisms regulate endocannabinoid signaling at multiple synapses in the ventral tegmental area. J Neurosci 24:11070-11078.

Sairanen M, O’Leary OF, Knuuttila JE, Castrén (2007) Chronic antidepressant treatment selectively increases expression of plasticity-related proteins in the hippocampus and medial prefrontal cortex of the rat. Neuroscience 144:368-374.

Shearman LP, Rosko KM, Fleischer R, Wang J, Xu S, Tong XS, Rocha BA (2003) Antidepressant-like and anorectic effects of the cannabinoid receptor inverse agonist AM251 in mice. Behav Pharmacol 14:573-582.

Tomasini MC, Ferraro L, Bebe BW, Tanganelli S, Cassano T, Cuomo V, Antonelli T (2002) Delta(9)-tetrahydrocannabinol increases endogenous extracellular glutamate levels in primary cultures of rat cerebral cortex neurons: involvement of $\mathrm{CB}_{1}$ receptors. J Neurosci 68:449-453.

Trettel J, Levine ES (2002) Cannabinoids depress inhibitory synaptic inputs received by layer $2 / 3$ pyramidal neurons of the neocortex. J Neurophysiol 88:534-539.

Tsou K, Brown S, Sanudo-Pena MC, Mackie K, Walker JM (1998) Immunohistochemical distribution of cannabinoid $\mathrm{CB}_{1}$ receptors in the rat central nervous system. Neuroscience 83:393-411.

Vieweg WV, Julius DA, Fernandez A, Beatty-Brooks M, Hettema JM, Pandurangi AK (2006) Posttraumatic stress disorder: clinical features, pathophysiology, and treatment. Am J Med 119:383-390.

Viveros MP, Marco EM, File SE (2005) Endocannabinoid system and stress and anxiety responses. Pharmacol Biochem Behav 81:331-342.

Volkow ND, Gillespie H, Mullani N, Tancredi L, Grant C, Ivanovic M, Hollister L (1991) Cerebellar metabolic activation by delta-9-tetrahydrocannabinol in human brain: a study with positron emission tomography and 18F-2-fluoro-2-deoxyglucose. Psychiatry Res 40:69-78.

Ware MA, Adams H, Guy GW (2005) The medicinal use of cannabis in the UK: results of a nationwide survey. Int J Clin Pract 59:291-295.

Wirtshafter D, Sheppard AC (2001) Localization of GABA(B) receptors in midbrain monoamine containing neurons in the rat. Brain Res Bull 56: $1-5$.

World Health Organization (2006) Annex 5.a: prevalence of use, adverse health effects of and interventions for-cannabis, cocaine, amphetamines and-MDMA use and dependence. In: Disease control priorities related to mental, neurological, developmental and substance abuse disorders, p 87. Geneva: Department of Mental Health and Substance Abuse, World Health Organization. 